\title{
Effect of Lactobacillus rhamnosus on Physicochemical Properties of Fermented Plant-Based Raw Materials
}

\author{
Carmen Masiá $^{1}$ (D), Poul Erik Jensen ${ }^{1}$ (D) and Patrizia Buldo ${ }^{2, *(D)}$ \\ 1 Department of Food Science, University of Copenhagen, Rolighedsvej 26, 1958 Frederiksberg, Denmark; \\ cala@food.ku.dk (C.M.); peje@food.ku.dk (P.E.J.) \\ 2 Food Cultures and Enzymes, Plant Based Application Projects \& Competences, Chr. Hansen A/S, \\ Bøge Alle 10-12, 2970 Hørsholm, Denmark \\ * Correspondence: dkpabu@chr-hansen.com
}

Received: 27 July 2020; Accepted: 16 August 2020; Published: 26 August 2020

\begin{abstract}
Texture and flavor are currently the main challenges in the development of plant-based dairy alternatives. To overcome them, the potential of microorganisms for fermentation of plant-based raw materials is generating great interest in the food industry. This study examines the effect of Lactobacillus rhamnosus, LGG ${ }^{\circledR}\left(\mathrm{LGG}^{\circledR}\right.$ is a trademark of Chr. Hansen A/S) on the physicochemical properties of fermented soy, oat, and coconut. LGG $^{\circledR}$ was combined with different lactic acid bacteria (LAB) strains and Bifidobacterium, BB-12 ${ }^{\circledR}\left(\mathrm{BB}-12^{\circledR}\right.$ is a trademark of Chr. Hansen A/S). Acidification, titratable acidity, and growth of LGG ${ }^{\circledR}$ and BB-12 ${ }^{\circledR}$ were evaluated. Oscillation and flow tests were performed to analyze the rheological properties of fermented samples. Acids, carbohydrates, and volatile organic compounds in fermented samples were identified, and a sensory evaluation with a trained panel was conducted. LGG ${ }^{\circledR}$ reduced fermentation time in all three bases. LGG ${ }^{\circledR}$ and $B B-12^{\circledR}$ grew in all fermented raw materials above $10^{7} \mathrm{CFU} / \mathrm{g}$. LGG ${ }^{\circledR}$ had no significant effect on rheological behavior of the samples. Acetoin levels increased and acetaldehyde content decreased in the presence of LGG ${ }^{\circledR}$ in all three bases. Diacetyl levels increased in fermented oat and coconut samples when LGG $^{\circledR}$ was combined with YOFLEX ${ }^{\circledR}$ YF-L01 and NU-TRISH ${ }^{\circledR}$ BY-01 (YOFLEX ${ }^{\circledR}$ and NU-TRISH ${ }^{\circledR}$ are trademarks of Chr. Hansen A/S). In all fermented oat samples, LGG $^{\circledR}$ significantly enhanced fermented flavor notes, such as sourness, lemon, and fruity taste, which in turn led to reduced perception of the attributes related to the base. In fermented coconut samples, gel firmness perception was significantly improved in the presence of LGG ${ }^{\circledR}$. These findings suggest supplementation of LAB cultures with LGG $^{\circledR}$ to improve fermentation time and sensory perception of fermented plant-based products.
\end{abstract}

Keywords: fermentation; plant-based; LAB; L. rhamnosus; rheology; flavor; sensory

\section{Introduction}

The demand for plant-based alternatives to fermented dairy products is increasing [1-3] and meeting consumer's expectations is a major challenge for food producers. Favorable organoleptic properties dominate over sustainability or health when it comes to consumer behavior [4]. In this regard, texture and flavor attributes play an important role in plant-based products [5] and their improvement is essential for successful product development. This can be achieved through fermentation [6], since the use of microorganisms facilitates the development of clean label products. Thereby, some of the main challenges that plant-based products currently face, such as excessive food processing or the use of additives, [7], can be avoided. In this context, it is crucial to understand the effect that bacterial cultures have on plant-based raw materials, focusing on their potential for sensorial and textural improvement of fermented plant-based products. A wide variety of plant-based substrates (i.e., bases) with different compositions are currently being studied $[1,8]$ with the goal of mimicking 
the functionality of dairy milk. Soybean has dominated for the past decades [1,9], but the portfolio of plant-based raw materials for plant-based fermented products has expanded into other legumes, nuts, seeds, pseudocereals, and cereals [2]. Soy [2,3,10], oat [11], and coconut [12] are some of the most popular substrates due to their nutritional value and/or their physicochemical properties.

Soy milk has the highest protein content among all plant-based milks (2.5-3.1 g per $100 \mathrm{~mL}$ [13]), and its amino acid profile resembles the one from bovine milk [14]. It contains lower saturated and higher mono- and polyunsaturated fat content than dairy milk [13]. However, storage globulins in soy are considered to be allergens [15], one of the reasons for consumer rejection. Soybeans also contain a high amount of galactooligosaccharides (GOSs), mainly raffinose and stachyose [16]. They are considered non-digestible oligosaccharides (NDOs) due to an absence of $\alpha$-galactosidase in human intestine [17]. For this reason, soy has gained bad reputation for generating bloating and gastrointestinal disorders [16]. Fermentation with lactobacilli has been proven to metabolize soy oligosaccharides [18]. Acidification of commercial soy drinks down to $\mathrm{pH} 3.5 \mathrm{after} 48 \mathrm{~h}$ of fermentation at $37^{\circ} \mathrm{C}$ has been reported [19]. Fermentation also contributes to the rheological characteristics of soy-based gels, as shown in numerous studies $[20,21]$. Soy protein gelation is the main feature in fermented soy gels [22] and it is affected by different factors, such as globulin (7S and 11S) ratios [23] in protein-polysaccharide blends and molecular weight of polysaccharides [22]. In addition, gelation of soy proteins can also be induced by enzymes. Transglutaminase induced soy protein gelation for plant-based yogurt with encapsulated probiotics [24]. Previous studies suggested that soy protein could have a similar isoelectric point to casein $[25,26]$ and its high gelation potential [22] could be influenced by its endogenous peptidases [27]. Moreover, combinations of bacterial strains could influence soy gels rheological properties. For instance, higher viscosity was observed with binary cultures fermentation, specifically with a combination of L. acidophilus and L. plantarum [25]. Fermented soy is associated with a characteristic beany flavor caused by lipid oxidation products (mostly pentanal and n-hexanal [28]). This limits its acceptance in occidental cultures. However, this can be overcome using different methods, such as pulse electrification or lipoxygenase treatment [29].

Oats have lately gained popularity due to their high nutritional value [30]. Their dietary fibers, specifically soluble fibers $\beta$-glucans found in the endosperm cell walls, are considered prebiotics. They serve as feed for the intestinal microflora, promoting bacterial growth during fermentation [31]. $\beta$-glucans also contribute to a regulation of satiety levels [32] and act as thickening agents, increasing product viscosity [33] and avoiding the addition of other functional ingredients or stabilizers [34]. Oat groats contain $15-20 \%$ protein [35] with a complete amino acid profile with almost all essential amino acids exceeding human requirements except for lysine and threonine [35]. Oat protein digestibility is generally high [36]. However, commercial oat-based milks present a protein deficiency ( $\leq 1 \mathrm{~g}$ per $100 \mathrm{~mL}$ of product) [3]. This questions their suitability as a substrate for yogurt- and cheese-like products, since proteins are an essential factor for texture formation in fermented materials [22,27]. Nevertheless, this can be solved with protein supplementation or by preparing a matrix from an oat concentrate. Globulins are the main proteins in oat and they have a similar structure to soy $11 \mathrm{~S}$ protein, also aggregating under $100{ }^{\circ} \mathrm{C}$ [37] and allowing gelation. The major component of oat groats carbohydrates is starch (40-60\%) [38] and its functionality has a positive effect on the rheological properties of fermented products, contributing to gelatinization. Oat lipids range from 2 to $13 \%$ and their oxidation is responsible for the off-flavor of oat-based products [39]. Volatile compounds generated through lipid oxidation, such as hexanal, pentanal, and certain carbonyl compounds [40,41], give oat drink an unpleasant aftertaste related to rancidity. Additionally, the presence of long-chain hydroxy fatty acids causes bitter off-notes in oat flavor [42]. These negative attributes should be masked to achieve consumer acceptance of an oat-based dairy alternative.

Coconut is another popular raw material for the development of plant-based products; especially its oil is used in cheese alternatives. It has the highest amount of fat and the lowest amount of protein [1]. Commercial coconut milk has ca. $1 \mathrm{~g}$ of protein or less and 4-6 $\mathrm{g}$ of fat per $100 \mathrm{~g}$ of product $[13,43] .87 \%$ of the fat is saturated [1] and it is mostly constituted by myristic acid, lauric acid, 
palmitic acid, and capric acid [14]. The high saturated fatty acids content in coconut oil enables the formation of a solid structure at ambient temperature with a small melting temperature range (18.3-26.4 ${ }^{\circ} \mathrm{C}$ [44]) influenced by short chain lauric acid [45]. Its ability to provide solid textures makes it a good candidate to obtain firmer products, such as non-dairy yogurt or non-dairy cheese, but, because of its lack of protein and high saturated fat content, it is not the most optimal replacement for dairy alternatives [13]. Coconut milk contains a low carbohydrate content (5.5 g/100 g of product) that can be reduced to $1.32 \mathrm{~g} / 100 \mathrm{~g}$ of product after fermentation [46]. Previous studies reported coconut milk as a favorable medium for probiotic bacterial growth [12] and for the preservation of cell viability after fermentation [9].

Fermentation is an essential process to transform plant-based raw material into non-dairy alternatives. Lactic acid bacteria (LAB) have been used since ancient times to ferment cereals, fruits, vegetables, meat, and milk, among others, with the preservation and organoleptic improvement purposes [6,47]. LAB are a group of gram-positive, non-spore-forming, facultative anaerobic bacteria whose main carbohydrate fermentation product is lactic acid [48]. LAB can generate an extended portfolio of aromatic compounds, endowing fermented products with characteristic flavors and aromas originated with the breakdown of the predominant macronutrients in the food matrix [49]. A wide range of alcohols, aldehydes, and acids are obtained from pyruvate precursors and amino acids metabolism. Certain LAB can produce exopolysaccharides (EPS), compounds that are known to improve texture in fermented products, increasing viscosity and improving stability [34]. This feature can enable the replacement of thickening agents. LAB that have already been used in the development of fermented plant-based dairy alternatives are L. delbrueckii [50], S. thermophilus, and L. delbrueckii subsp. bulgaricus [10], B. longum or L. rhamnosus [51]. In order to observe synergistic effects similar to those in dairy fermentation, plant-based fermentation with pure and mixed cultures has been evaluated [52]. It was found that both pure and mixed cultures are suitable for oat fermentation, but pure cultures showed better flavor profiles. In the current study, different cultures were combined with Lactobacillus rhamnosus, $\mathrm{LGG}^{\circledR}$, a registered trademark of Chr. Hansen A/S identifying the L. rhamnosus strain and related products. LGG ${ }^{\circledR}$ is one of the world's most documented probiotic strains. It originates from human intestinal microbiota and has been used worldwide since 1990. Previous studies showed that L. rhamnosus can grow in bases containing cereals and pseudocereals $[11,53,54]$ and lower the $\mathrm{pH}$. $\mathrm{LGG}^{\circledR}$ has a strong proteolytic capacity and it is able to produce exopolysaccharides (EPS) in dairy milk [55], which characterizes it as a functional starter culture [56]. Its functionality has been studied in plant-based raw materials [57]. EPS were detected in oat fermented with EPS-producing strains. In a later study, it was reported that EPS production takes place at lower temperatures than growth temperature, which indicates that EPS are produced after fermentation [58]. Their contribution to product viscosity $[8,33]$ and prevention of phase separation in oat yogurts fermented with EPS-producing strains was also highlighted. Polysaccharide production is conditioned by the presence of different sugars in varying amounts in the base (i.e., growth media) [59]. Lactose, galactose, glucose were remarked as the most efficient carbon sources for EPS production with L. rhamnosus [59]. This strain has also been used in studies that involve the fermentation of different legumes [53], cereals [54], coconut, and hemp [9]. All of the studies reported its ability to grow and lower the $\mathrm{pH}$ of the media and no negative effects on its viability or on the sensory properties of the final products. Nevertheless, further research is being carried on for a deeper understanding of probiotics in plant-based fermentation. One of the world's other most documented strains is BB-12 ${ }^{\circledR}$ Bifidobacterium, also a trademark of Chr. Hansen A/S. Satisfactory growth of BB-12 ${ }^{\circledR}$ in fermented soy with different carbohydrate content has been reported [60]. In addition, $\alpha$-galactosidase activity of BB-12 ${ }^{\circledR}$ can reduce GOSs content in soy milk. Viability of BB-12 ${ }^{\circledR}$ was likewise shown in a soy dessert during 6 months of storage at colony forming units (CFU) levels above $10^{7} \mathrm{CFU} / \mathrm{g}$ [4]. It has been suggested that soy milk and coconut milk could be richer media for BB-12 ${ }^{\circledR}$ growth due to their amino acids profile in comparison to dairy milk [61]. 
The objective of this study was to investigate the growth and viability of LGG ${ }^{\circledR}$ and BB-12 ${ }^{\circledR}$ in fermented plant bases. Soy, oat, and coconut were selected as substrates to cover a broad spectrum of plant-based raw materials: legumes, cereals, and high fat substrates, respectively. In addition, the synergy of LGG ${ }^{\circledR}$ and different starter cultures, including BB- $12^{\circledR}$, and their effect on physicochemical and sensory properties were studied. It was intended to demonstrate the growth of both probiotic strains in plant materials above $10^{7} \mathrm{CFU} / \mathrm{g}$, overtaking the recommended levels for a beneficial effect on human intestinal health $\left(10^{6} \mathrm{CFU} / \mathrm{g}\right)[62,63]$.

\section{Materials and Methods}

For each base, three separate batches were produced; for each batch, duplicate measurements were taken in all the experiments.

\subsection{Preparation and Fermentation of Plant Bases}

The raw materials used for the preparation of the bases were soy milk (Naturli Foods, Vejen, Denmark), coconut milk (Aroy-D, Thai Agri Foods, Samut Prakan, Thailand), oat concentrate (Oatvita, Frulact, Tortosendo, Portugal), sucrose (Nordic Sugar, København, Denmark), and starch (Clearam CJ5025, Roquette, Frankfurt am Main, Germany). The preparation of the media was performed following the composition that is shown in Tables 1 and 2. Ingredients were mixed until obtaining a homogeneous matrix. Oat concentrate was previously subjected to an enzymatic treatment (partial hydrolysis and saccharification of starch) followed by a heat treatment.

Table 1. Composition of the plant bases.

\begin{tabular}{cc}
\hline Base & Composition \\
\hline Soy & $95 \%$ soy milk, $5 \%$ sucrose \\
Oat & $30 \%$ w $/ w$ oat concentrate \\
Coconut & $93 \%$ coconut milk, $3 \%$ sucrose, $4 \%$ starch \\
\hline
\end{tabular}

Table 2. Nutritional content of the unfermented bases produced for this study.

\begin{tabular}{ccccc}
\hline Base & Protein (\%) & Carbohydrates (\%) & Main Sugar & Fat (\%) \\
\hline Soy & 3.7 & 5 & Sucrose & 2 \\
Oat & 4.5 & 18 & Glucose & 2.2 \\
Coconut & 1.49 & 3 & Sucrose & 17.67 \\
\hline
\end{tabular}

Sample size for base fermentation oscillated between three and five liters. Soy, oat, and coconut bases were pasteurized at $90{ }^{\circ} \mathrm{C}$ for $20 \mathrm{~min}$ and cooled at the fermentation temperature of $43{ }^{\circ} \mathrm{C}$. The cultures used for the fermentation of the plant bases were provided by Chr. Hansen A/S (Hørsholm, Denmark) and they are shown in Table 3. Samples were inoculated with $0.02 \%$ of either YOFLEX ${ }^{\circledR}$ YF-L01 DA (YF-L01), YOFLEX ${ }^{\circledR}$ YF-L02 DA (YF-L02), and NU-TRISH ${ }^{\circledR}$ BY-01 DA (BY-01) separately and with a combination of each of the previous cultures with LGG $^{\circledR}$. A total of six different culture combinations were inoculated in each base.

Table 3. List of bacterial cultures used for the fermentation of the plant bases.

\begin{tabular}{|c|c|}
\hline Culture Name & Composition \\
\hline YOFLEX ${ }^{\circledR} *$ YF-L01 DA (YF-L01) & Streptococcus thermophilus \\
\hline YOFLEX ${ }^{\circledR} *$ YF-L02 DA (YF-L02) & $\begin{array}{l}\text { Streptococcus thermophilus and Lactobacillus bulgaricus supplemented with } \\
\text { Lactobacillus acidophilus, Lactobacillus paracasei, and Bifidobacterium }\end{array}$ \\
\hline NU-TRISH ${ }^{\circledR} *$ BY-01 DA (BY-01) & Streptococcus thermophilus and Lactobacillus bulgaricus with Bifidobacterium, BB-12 ${ }^{\circledR}$ \\
\hline LGG $^{\circledR}$ & Lactobacillus rhamnosus \\
\hline
\end{tabular}


$\mathrm{pH}$ variation was measured at intervals of 4 min with iCinac (AMS S.R.L., KPM Analytics, Rome, Italy) until the samples reached $\mathrm{pH}$ 4.5. Afterwards, the coagulum was broken with a perforate disc and a cooling and a smoothing process $\left(25^{\circ} \mathrm{C}\right.$ and two bars back-pressure) were applied. The samples were stored at $6{ }^{\circ} \mathrm{C}$.

\subsubsection{Post Acidification and Titratable Acidity during Storage}

Post acidification of fermented samples was measured with a standard $\mathrm{pH}$-meter at day 1,7 , 14, and 21. Acidimetric titration of fermented samples was performed by auto-titrator InMotion Pro (Mettler Toledo, Columbus, OH, USA). Samples of 5-15 g of fermented product were mixed with demineralized water in a disposable titration breaker (Mettler Toledo, Columbus, OH, USA) up to $60 \mathrm{~g}$ without stirring. The samples were titrated against a $0.1 \mathrm{M}$ sodium hydroxide $(\mathrm{NaOH})$ solution and analyzed in duplicates. The equation used to calculate titratable acidity (TA) values was as follows:

$$
\mathrm{TA}(\% \text { lactic acid })=\frac{(\mathrm{mL} 0.1 \mathrm{~N} \mathrm{NaOH} \times 0.9)}{\mathrm{g} \text { sample }}
$$

The molecular weight of lactic acid (90.08) is used as a constant in the equation (0.9). Buffer solutions ( $\mathrm{pH} 4.01, \mathrm{pH} \mathrm{7}$, and $\mathrm{pH} 9.21$ at $20^{\circ} \mathrm{C}$ ) used for titratable acidity and post-acidification $\mathrm{pH}$ measurements were provided by Hamilton Nordic AB (Kista, Denmark) and $\mathrm{NaOH}$ was obtained from VWR (Søborg, Denmark).

\subsubsection{Cell Growth during Storage}

For the selective cell count of Lactobacillus rhamnosus, LGG ${ }^{\circledR}$ and Bifidobacterium, BB-12 ${ }^{\circledR}$, different growth media were prepared. The colony forming units count of LGG $^{\circledR}$ was performed on De Man, Rogosa y Sharpe (MRS) 6.5 agar media (BD Difco, NJ, USA) with $100 \mu \mathrm{L}$ of vancomycin (internal solution) per $200 \mathrm{~mL}$. The colony forming units count of BB-12 ${ }^{\mathbb{R}}$ was performed on MRS 6.5 agar media with $1 \mathrm{~mL}$ of cystein hydrochloride $10 \%$ (CyHCl) (Merck, Søborg, Denmark), and $300 \mu \mathrm{L}$ of lithium mupirocin (MUP) (Sigma Aldrich, Søborg, Denmark) per $200 \mathrm{~mL}$. Vancomycin and MUP inhibit the growth of enterococci and lactic acid bacteria that could be present in the samples. They do not affect the growth of $L G G{ }^{\circledR}$ and $B B-12^{\circledR}$, respectively, enabling the selective enumeration of colonies of interest. Initial samples were thoroughly mixed and stirred. The first dilution was prepared with $5 \mathrm{~g}$ of each sample in $45 \mathrm{~g}$ of sterile peptone saline diluent (Oxoid, Roskilde, Denmark) in sterile stomacher bags. The samples were mixed during $1 \mathrm{~min}$ at $230 \mathrm{rpm}$ to ensure homogeneity and serial 10-fold dilutions were prepared. Each dilution was vortexed for $3 \mathrm{~s}$. $1 \mathrm{~mL}$ of each dilution was inoculated in empty Petri dishes and 12-15 mL of previously prepared melted MRS agar media with vancomycin for LGG ${ }^{\circledR}$ count was poured into the Petri dish. The same procedure was performed with MRS media with $\mathrm{CyHCl}$ and MUP for BB- $12{ }^{\circledR}$ count. Diluted samples and growth media were mixed by moving the Petri dishes in circular movements without incorporation of air. After solidification of the medium, all Petri dishes were incubated at $37^{\circ} \mathrm{C}$ for three days in an inverted position under anaerobic conditions. After the incubation period, plates with 15 to 300 colonies were selected for cell count and verified by microscopy. The results were reported as colony forming units per gram $(\mathrm{CFU} / \mathrm{g})$.

\subsection{Physicochemical Analysis of Fermented Bases}

\subsubsection{Rheological Measurements}

Rheological experiments were performed after seven days of storage. A flow test and an oscillation test were performed with a rheometer MCR 302 (Anton Paar GmbH, Graz, Austria). A stainless-steel coaxial cylinder (CC27 system, stator inner radius $28.9 \mathrm{~mm}$, rotor outer radius $26.7 \mathrm{~mm}$, height $40 \mathrm{~mm}$, gap $1.130 \mathrm{~mm}$ ) was used. The oscillation test was performed between $0.5-8 \mathrm{~Hz}$ at constant strain, and complex modulus $\left(\mathrm{G}^{*}\right)$, storage modulus $\left(\mathrm{G}^{\prime}\right)$ and loss modulus $\left(\mathrm{G}^{\prime \prime}\right)$ 
were measured. Complex modulus at a frequency of $1.52 \mathrm{~Hz}$ were used for the statistical comparison of all samples based on a previous internal study. The flow test was performed with shear rates $(\gamma)$ from $10^{-3} \mathrm{~s}^{-1}$ to $300 \mathrm{~s}^{-1}$ for the up-flow and from $300 \mathrm{~s}^{-1}$ to $10^{-3} \mathrm{~s}^{-1}$ for the down-flow. Shear stress $(\tau)$ was measured for each of the samples. Shear stress values for $45.2 \mathrm{~s}^{-1}$ shear rates were statistically compared, according to previous findings about oral perception of thickness being strongly correlated to deformation measurements for viscosity at a shear rate of $50 \mathrm{~s}^{-1}$ [64]. The hysteresis loop area between up-flow curve and down-flow curve was also calculated.

\subsubsection{Identification of Carbohydrates and Acids}

Ion chromatography on Dionex systems $2-4$ was performed to identify acids and carbohydrates present in all fermented samples. All of the chemicals as well as analytes used for the standard solutions were provided by Sigma-Aldrich, Munich, Germany. Internal standard solutions following Dionex methods and a perchloric acid (PCA) protein precipitation solution were prepared. For the latter, $6.9 \mathrm{~mL}$ PCA were mixed with $20 \mathrm{~mL} \mathrm{0.1} \mathrm{M} \mathrm{disodium} \mathrm{ethylenediaminetetraacetate} \mathrm{dehydrate}$ ( $\left.\mathrm{Na}_{2}-\mathrm{EDTA}\right)$, and Milli-Q Water (MQW) (Merck-Millipore, Merck KGaA, Darmstadts, Germany) was added to a final volume of $1.000 \mathrm{~mL}$. For the preparation of samples without sucrose (oat samples), $1 \mathrm{~g}$ or $1 \mathrm{~mL}$ of sample was quenched with $200 \mu \mathrm{L} 4 \mathrm{~N}$ sulfuric acid $\left(\mathrm{H}_{2} \mathrm{SO}_{4}\right)$ in a $7 \mathrm{~mL}$ glass tube, mixed and stored at $-20{ }^{\circ} \mathrm{C}$ until analysis. For the preparation of samples with sucrose (soy and coconut samples), $1 \mathrm{~g}$ or $1 \mathrm{~mL}$ sample was quenched with $2 \mathrm{~mL}$ ice-cold $\left(-20^{\circ} \mathrm{C}\right) 96 \%$ ethanol in $7 \mathrm{~mL}$ glass tube, mixed and stored at $-20^{\circ} \mathrm{C}$ ) until analysis. Acids standards were prepared by weighing exact amounts of each acid and transferring them to a $200 \mathrm{~mL}$ volumetric flask. $150 \mathrm{~mL}$ MQW was added and after ensuring that all acids were completely dissolved, $\mathrm{pH}$ was adjusted to $\mathrm{pH}$ to 8-9 with $4 \mathrm{M}$ carbonate-free $\mathrm{NaOH}$. The carbohydrate standards were weighed in exact amounts and dissolved in the acid mix. The flask was filled up to $200 \mathrm{~mL}$ with MQW and well mixed to ensure that all solids were completely dissolved. Two types of controls were prepared: systemic controls to tack the systems performance and matrix controls to calculate the variation within each individual sequence. Systemic controls were prepared by adding $0.5 \mathrm{~mL}$ basic standard solution and $1 \mathrm{~mL}$ internal standard solution at room temperature in a $500 \mathrm{~mL}$ volumetric flask. $300 \mathrm{~mL}$ MQW were added, well mixed and filled up to $500 \mathrm{~mL}$. The solution was aliquoted into HPLC vials adding $1.5 \mathrm{~mL}$ per vial and stored at $-20{ }^{\circ} \mathrm{C}$ until use. For the matrix controls, a $100 \mathrm{~g}$ sample was transferred to a $500 \mathrm{~mL}$ blue cap flask and quenched by adding $20 \mathrm{~mL}$ of $4 \mathrm{~N} \mathrm{H}_{2} \mathrm{SO}_{4}$ and protein precipitated with $180 \mathrm{~mL}$ PCA solution. The solution was stirred for $30 \mathrm{~min}$, distributed into $50 \mathrm{~mL}$ falcon tubes, and centrifuged for $15 \mathrm{~min}$ at $2.800 \mathrm{~g}\left(4^{\circ} \mathrm{C}\right)$. The supernatant was taken out $(150 \mathrm{~mL})$ and pooled, adjusting $\mathrm{pH}$ to 8-9 with carbonate-free $\mathrm{NaOH}$ (app. 15-20 mL). The same standards are used for samples with and without sucrose. $\mathrm{pH}$ was readjusted with ca. $5 \mathrm{~mL} \mathrm{NaOH}$ and transferred to a $200 \mathrm{~mL}$ volumetric flask that was filled up to $200 \mathrm{~mL}$ with MQW, ensuring that all of the standards were properly dissolved. For each analytical series, a blank sample $(1 \mathrm{~mL} \mathrm{MQW})$ as well as the relevant standard $(1 \mathrm{~mL})$ and control are prepared in the same way as the actual samples. To samples without sucrose (oat samples), $1.8 \mathrm{~mL}$ of PCA solution and $2 \mathrm{~mL}$ internal standard solution were added to each sample. To the correspondent blanks, standards, and controls, $200 \mu \mathrm{L} 4 \mathrm{~N} \mathrm{H}_{2} \mathrm{SO}_{4}, 1.8 \mathrm{~mL}$ of PCA solution, and $2 \mathrm{~mL}$ internal standard solution were added. To samples with sucrose, $2 \mathrm{~mL}$ internal standard solution were added. To the correspondent blanks, standards, and controls, $2 \mathrm{~mL}$ ice-cold $\left(-20^{\circ} \mathrm{C}\right) 96 \%$ ethanol and $2 \mathrm{~mL}$ internal standard solution were added. All of the samples were centrifuged for $30 \mathrm{~min}\left(2.800 \mathrm{~g}, 4^{\circ} \mathrm{C}\right)$ and tubes were directly transferred to Perkin-Elmer robot. Samples were diluted five times and those with a solid layer of supernatant on top after centrifugation were filtered with $0.45 \mu \mathrm{m}$ filter into a $7 \mathrm{~mL}$ tube. 


\subsection{Identification of Volatile Organic Compounds (VOCs)}

\subsubsection{Identification of Targeted VOCs}

The identification of targeted (VOCs) was performed with a static head space sampler connected to a Gas Chromatograph with Flame Ionization Detector (GC-FID) (Perkin Elmer, MA, USA) and equipped with a HP-FFAP column (length: $25 \mathrm{~m}$; internal diameter: $0.20 \mathrm{~mm}$; layer thickness: $0.33 \mu \mathrm{m}$; Agilent Technologies, Glostrup, Denmark). Helium was selected as the carrier gas. The chemicals that were used for dilution and acidification were 1-methyl-2-pyrrolidone, MQW, and $4 \mathrm{~N} \mathrm{H}_{2} \mathrm{SO}_{4}$. The compounds for the preparation of the standards were the following: acetone (100 mg), acetaldehyde (100 mg), ethyl acetate (100 mg), 3-methyl butanal (100 mg), ethanol (100 mg), diacetyl (100 mg), butan-1-ol (500 mg), and acetoin (500 mg). The chemicals were weighed and transferred to a $100 \mathrm{~mL}$ measuring flask containing ca. $50 \mathrm{~mL}$ methyl-pyrrolidone. Acetaldehyde was weighted as the last compound due to its volatility. Methyl-pyrrolidone was added until $100 \mathrm{~mL}$ and stirred for $10 \mathrm{~min}$. This was equivalent to a $1000 / 5000 \mathrm{ppm}$ solution. $1 \mathrm{~mL}$ of the stock solution was added to $99 \mathrm{~mL}$ MQW in a measuring flask and mixed carefully. This was equivalent to a 10/50 ppm solution. For the analysis of the standard solution, 10 headspace vials $(20 \mathrm{~mL})$ with $1 \mathrm{~mL}$ of the prepared standard plus $200 \mu \mathrm{L} 4 \mathrm{~N} \mathrm{H}_{2} \mathrm{SO}_{4}$ were prepared, sealed with teflon-lined aluminium caps and analyzed on the day of preparation. The remaining volume of the calibration solution was used as aqueous control solution. It was frozen in tubes containing $3 \mathrm{~mL}$, sealed and stored at $-18{ }^{\circ} \mathrm{C}$ prior to analysis. On the day of analysis, the solution was thawed and $1 \mathrm{~mL}$ of the solution was transferred to headspace vials with $200 \mu \mathrm{L} 4 \mathrm{~N} \mathrm{H}_{2} \mathrm{SO}_{4}$ and sealed with teflon-lined aluminium caps. Kovats retention index solution (KI) was prepared with a mix of $25 \mu \mathrm{L}$ hexane, $25 \mu \mathrm{L}$ heptane, $40 \mu \mathrm{L}$ octane, $80 \mu \mathrm{L}$ nonane, $160 \mu \mathrm{L}$ decane, $360 \mu \mathrm{L}$ undecane, $640 \mu \mathrm{L}$ dodecane, $2500 \mu \mathrm{L}$ tridecane, $100 \mu \mathrm{L}$ 1-heptanol, $500 \mu \mathrm{L}$ 1-octanol, and $1000 \mu \mathrm{L}$ 1-nonanol, from which $25 \mu \mathrm{L}$ were transferred to $20 \mathrm{~mL}$ vials. For the preparation of the samples, $1 \mathrm{~mL}$ of each sample was transferred to a headspace vial ( $20 \mathrm{~mL}$ ) with $200 \mu \mathrm{L}$ of $4 \mathrm{~N} \mathrm{H}_{2} \mathrm{SO}_{4}$ and sealed with teflon-lined aluminium caps. The samples were analyzed with Masked Clean Air for volatile compounds (MCA-VOC) method with a split flow of $10 \mathrm{~mL} / \mathrm{min}$. The identification of VOCs was based on retention time in comparison with that of standards. The injector and detector were maintained at $180{ }^{\circ} \mathrm{C}$ and $220^{\circ} \mathrm{C}$, respectively. The oven was initially heated to $60{ }^{\circ} \mathrm{C}$ and held for $2 \mathrm{~min}$, then increased to $230{ }^{\circ} \mathrm{C}$ and held for $0.5 \mathrm{~min}$. The calculation of the concentration of each compound in each sample was based on the peak height divided by the response factor (Equation (2)). The response factor was previously established with the standard solutions by the quotient of the peak height divided by the known sample concentration.

$$
\text { Sample concentration }=\frac{\text { Peak height }}{\text { Response factor }}
$$

2.3.2. Identification of Untargeted VOCs

For the analysis of untargeted VOCs, Gas Chromatography and Mass Spectrometry (GC-MS) was performed. The chromatographer was equipped with a column DB-5M (length, $30 \mathrm{~m}$; internal diameter, $0.25 \mathrm{~mm}$; layer thickness, $1 \mu \mathrm{m}$; Agilent Technologies, Glostrup, Denmark). It was coupled to a MS-detector equipped with Solid Phase Micro Extraction (SPME, Multi-Purpose Sampler, Gerstel, Skovlunde, Denmark) for identification and relative quantification of volatiles. A $2 \mathrm{~cm}$ fiber (DVB/Carboxen/PDMS, Supelco) was used for the analysis. Helium was selected as the carrier gas. Prior to analysis, a KI solution containing linear alkanes from $C_{5}$ to $C_{20}$ was prepared according to an internal protocol. For the internal standard solutions (IS), $10 \mathrm{~g} / \mathrm{L}$ stock solutions of ethanol-d6, dimethyl-d6 disulfide, 2-methyl-3-meptanone, and pyrazine-d4 were prepared by dissolving in 1-Methyl-2-pyrrolidone. All four IS stock solutions were stored at $-80{ }^{\circ} \mathrm{C}$. In a $200 \mathrm{~mL}$ measuring flask, approximately $150 \mathrm{~mL}$ water was added and the individual IS stock solutions were added according to previously defined ratios. The measuring flask was filled to $200 \mathrm{~mL}$ with water as diluent. 
At this concentration level, the expected signal-to-noise values for all compounds was of around 50 . IS-solutions were stored at $-18^{\circ} \mathrm{C}$.

For the sample preparation, $1 \mathrm{~mL}$ or $1 \mathrm{~g}$ of fermented sample was dispensed into a $20 \mathrm{~mL}$ vial with $100 \mu \mathrm{L}$ IS solution and stored at $-18{ }^{\circ} \mathrm{C}$ until analysis. Fermented samples were analyzed after a blank sample and the retention index sample (KI). GC was performed at an initial temperature of $32{ }^{\circ} \mathrm{C}$ that gradually increased to $325^{\circ} \mathrm{C}$. The incubation temperature and time for the SPME were $10 \mathrm{~min}$ and $60^{\circ} \mathrm{C}$, respectively. Penetration distance of the fiber in the vial was $30 \mathrm{~mm}$ and extraction time was $20 \mathrm{~min}$. Volatiles were adsorbed or absorbed onto the SPME fiber. The fiber was retracted and injected into the GC inlet at $60 \mathrm{~mm}$ distance, liberating volatiles to be separated in the column and detected by MS. Fiber was desorbed for $2 \mathrm{~min}$. The results were analyzed with MatLab and reported as relative signal-to-noise values for each sample (Equation (3)).

$$
\mathrm{S} / \mathrm{N}=\frac{\text { Height }_{\text {analyte }}}{\text { Height }_{\mathrm{IS}} \times \text { Noise }_{\text {analyte }}}
$$

Chemicals for targeted and untargeted VOCs identification were obtained from Sigma-Aldrich (Munich, Germany), except from 1-Methyl-2-pyrrolidone, which was purchased from Merck (Merck KGaA, Darmstadts, Germany).

\subsection{Sensory Analysis}

Descriptive analysis of the fermented samples was performed by a trained sensory panel composed of nine trained panelists. A training session took place before the tasting session to familiarize the panelists with the samples and to define the attributes to be evaluated. Three different sessions took place, one for each fermented base, and six samples were presented per session, corresponding to the six different culture combinations. The samples were evaluated in duplicate, in a randomized order and following a Latin square design. The identified attributes were rated on a five-level scale of perceived intensity from "none" to "a lot". Table 4 shows the definitions and indications established for the evaluation of the most complex attributes.

Table 4. List of attributes evaluated during the sensory analysis.

\begin{tabular}{|c|c|c|}
\hline Attribute & Definition & Indications \\
\hline Gel firmness & Resistance to deformation of the product. & $\begin{array}{l}\text { Slowly take a spoon of the product and place it on } \\
\text { the untouched sample surface. Note how long it keeps its shape. }\end{array}$ \\
\hline Ropiness & $\begin{array}{l}\text { Sticky, glutinuous or soft } \\
\text { nature of the product. }\end{array}$ & $\begin{array}{l}\text { Dip the bottom of the spoon several times fast in the surface } \\
\text { of the sample. A long string indicates high ropiness. }\end{array}$ \\
\hline Astringency & Similar feeling to very unripe fruit. & If the sample dries out your mouth, it means high astringency. \\
\hline Mouth coating & $\begin{array}{l}\text { The extent to which the product coats } \\
\text { the palate and teeth during mastication. }\end{array}$ & $\begin{array}{l}\text { Distribute the product in your mouth and swallow it. If it leaves a } \\
\text { coating in your mouth, it is high in mouth coating. }\end{array}$ \\
\hline Mouth thickness & Sensation of sample consistency in mouth. & $\begin{array}{l}\text { Evaluate the product's resistance when swallowed } \\
\text { with normal speed without tasting the sample. }\end{array}$ \\
\hline Smoothness & $\begin{array}{l}\text { The smoothness against the palate as } \\
\text { it breaks up during mastication. }\end{array}$ & $\begin{array}{l}\text { Perceive the smoothness of the sample by } \\
\text { squeezing it between palate and tongue. }\end{array}$ \\
\hline Acetic & Acidic smell of vinegar. & Hold your nose to perceive acidic flavor. \\
\hline Cardboard & $\begin{array}{l}\text { Aromatic associated with slightly oxidized fats, } \\
\text { reminiscent of wet cardboard packaging. }\end{array}$ & Tasting of the sample. \\
\hline Fatty/creamy & $\begin{array}{l}\text { Feeling associated with heavy } \\
\text { whipping cream. }\end{array}$ & $\begin{array}{l}\text { Compare the product with the given } \\
\text { full fat cream }(38 \%) \text { sample. }\end{array}$ \\
\hline Foamy & Foam appearance of the sample. & Visual evaluation of the sample. \\
\hline Powdery/chalky & Powder sensation in mouth. & Visual evaluation of the sample. \\
\hline Pudding-like & Similar structure to a pudding. & Visual evaluation of the sample. \\
\hline Shininess & $\begin{array}{c}\text { How shiny the surface of the product } \\
\text { looks like. }\end{array}$ & Visual evaluation of the sample. \\
\hline
\end{tabular}




\subsection{Statistical Analysis}

Statistical analysis of obtained data was performed with SPSS. Three-way analysis of variance (ANOVA) and Tukey tests were performed for the analysis of fermentation times, post-acidification, TA, cell growth, VOCs, acids, carbohydrates, and rheology data. Sensory data were analyzed with two-way ANOVA. Statistical evaluation of the results for the intensity perception included three-way MANOVA (multivariate analysis of variance) with Wilks test to identify the overall sample differences and ANOVA to find for which attribute there were significant differences, both considering the factors product, judge and replicate as well as their two-way interactions. The Least Significant Difference (LSD) test was used to detect significant differences among the product samples when the attributes had a significant product effect. Rolling correlations were performed with rheological experimental measurements and sensory perception data. Correlation coefficients between 1 and 0.6 and between -1 and -0.6 were accepted as significant. Principal Component Analysis (PCA) was performed to correlate VOCs and flavor attributes for each of the bases and all culture combinations. For all statistical analyses, except for the rolling correlations, significant differences were assumed at $95 \%$ confidence intervals $(p<0.05)$.

\section{Results}

\subsection{Effect of $L G G^{\circledR}$ in Acidification Time}

The time needed to reach $\mathrm{pH} 4.5$ for all samples was compared to identify differences across bases and a potential effect of LGG ${ }^{\circledR}$ on acidification (Table 5). There was a significant difference between the fermentation time in the three bases. This was related to their carbohydrates content and to the initial $\mathrm{pH}$ of the unfermented bases. $\mathrm{pH}$ of unfermented soy, oat, and coconut were 6.96, 6.16, and 5.96, respectively. Coconut samples needed shorter times to reach $\mathrm{pH} 4.5$ and the initial $\mathrm{pH}$ was lower in comparison to the other two bases. Therefore, the $\mathrm{pH}$ drop was smaller. However, the initial $\mathrm{pH}$ in unfermented oat samples was lower than in unfermented soy samples, and the former needed more time to reach $\mathrm{pH} 4.5$ than the latter. A reasonable explanation could be attributed to the buffering capacity of oat samples, since it was the base with higher protein content. Its globulins may have caused the need for a higher production of acid to decrease the $\mathrm{pH}$ and consequently fermentation time was increased. In fermented soy samples, the three culture combinations containing LGG $^{\circledR}$ needed ca. $1 \mathrm{~h}$ less to reach $\mathrm{pH} 4.5$ in comparison to those without $\mathrm{LGG}^{\circledR}$. In fermented oat samples, $\mathrm{LGG}^{\circledR}$ also decreased in ca. $1 \mathrm{~h}$ and a half the fermentation time when combined with YF-L01, YF-L02, and BY-01. In fermented coconut samples, there was no significant difference between culture combinations and, therefore, $\mathrm{LGG}^{\circledR}$ did not affect fermentation time.

Table 5. Fermentation time in hours required to reach $\mathrm{pH} 4.5$ in all fermented bases.

\begin{tabular}{cccc}
\hline \multirow{2}{*}{ Culture Combination } & \multicolumn{3}{c}{ Base } \\
\cline { 2 - 4 } & Soy & Oat & Coconut \\
\hline YF-L01 & $7.09 \pm 0.10^{A c}$ & $8.57 \pm 0.07^{B d}$ & $5.32 \pm 1.18^{C}$ \\
YF-L02 & $6.64 \pm 0.10^{A b}$ & $7.38 \pm 0.03^{B b c}$ & $5.11 \pm 1.26^{C}$ \\
BY-01 & $6.91 \pm 0.10^{A b c}$ & $7.94 \pm 0.05^{B c}$ & $5.70 \pm 1.16^{C}$ \\
YF-L01+LGG $^{\circledR}$ & $6.27 \pm 0.07^{A a}$ & $7.27 \pm 0.05^{B b}$ & $5.33 \pm 1.40^{C}$ \\
YF-L02+LGG $^{\circledR}$ & $6.02 \pm 0.10^{A a}$ & $6.65 \pm 0.13^{B a}$ & $5.43 \pm 1.18^{C}$ \\
BY-01+LGG $^{\circledR}$ & $6.05 \pm 0.23^{A a}$ & $6.80 \pm 0.09^{B a b}$ & $5.93 \pm 1.16^{C}$ \\
\hline
\end{tabular}

$A B C$ Means with different uppercase superscripts indicate significant differences between different columns $(p<0.05){ }^{a b c}$ Means in the same column with different lowercase superscripts indicate significant differences between different culture combinations $(p<0.05)$. 


\subsection{Changes during Storage}

\subsubsection{Post-Acidification and Titratable Acidity}

Post-acidification and titratable acidity of all fermented samples after day 1, 7, 14, and 21 were evaluated to understand changes in acidity during storage. Results are shown in Figure 1.
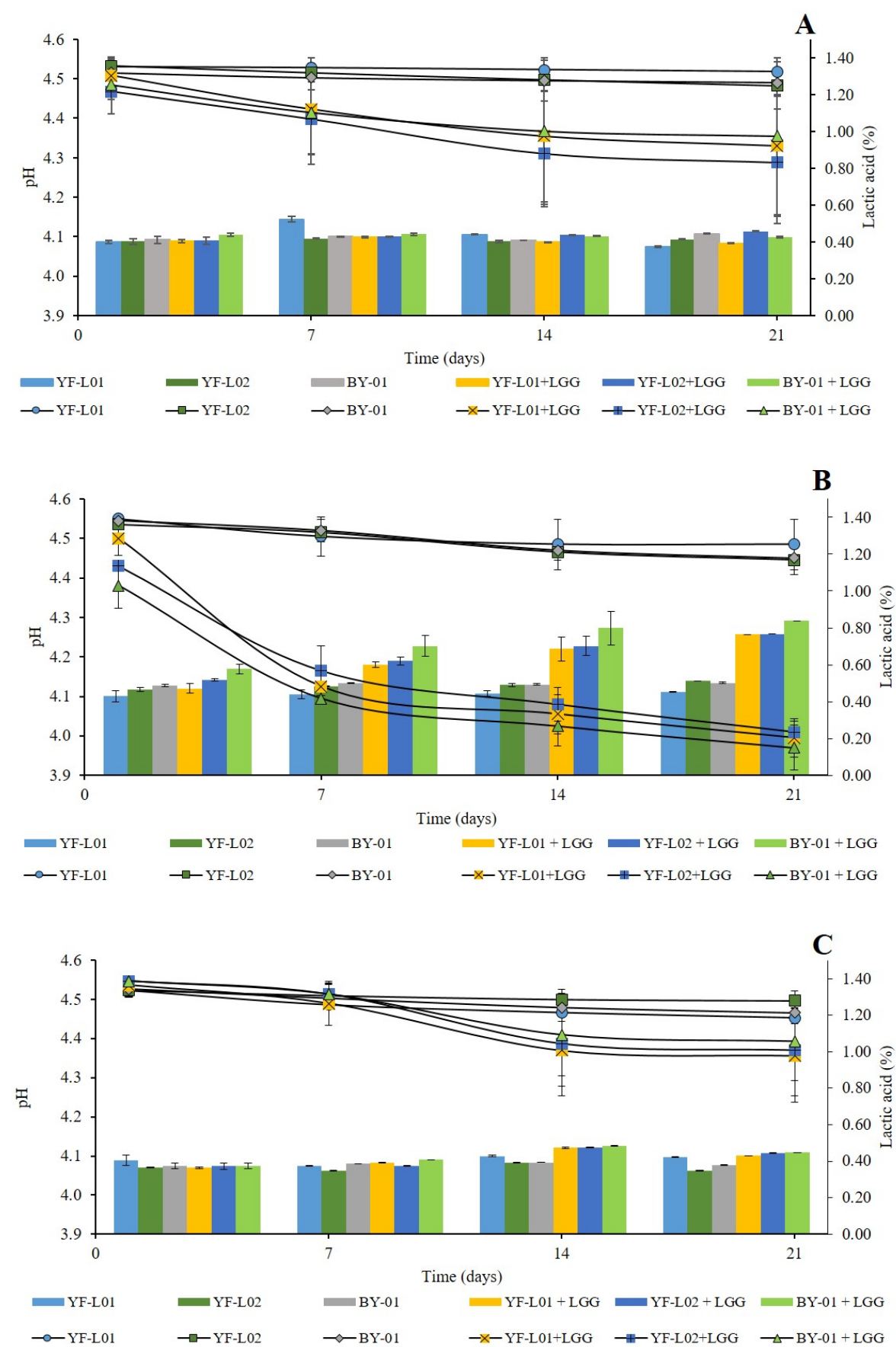

Figure 1. $\mathrm{pH}$ changes and titratable acidity of fermented (A) soy, (B) oat, and (C) coconut samples during storage at $6{ }^{\circ} \mathrm{C}$ for 21 days.

Oat samples showed significantly different post-acidification trends in comparison to soy and coconut when LGG ${ }^{\circledR}$ was present in culture combinations. In the two latter bases, there was no clear difference in acidification patterns in regards to the culture combinations. In contrast, in oat samples (Graph B, Figure 1, the presence of LGG ${ }^{\circledR}$ in the culture combination contributed to a more drastic 
post-acidification and to higher lactic acid levels. These samples reached $\mathrm{pH}$ values around four after 21 days of storage. This difference can be justified by a higher glucose content in the oatbase (Table 2), which could have encouraged LGG ${ }^{\circledR}$ to keep growing and producing lactic acid after fermentation [65], especially at the latest stages of the storage period. This result concurs well with the findings of Helland et al. [66]. They demonstrated the highest lactic acid production by L. rhamnosus in comparison to other Lactobacillus strains in a plant-based blend. TA of fermented oat in this study was higher than the one reported by Bernat et al. [65]. The highest value was $0.84 \%$ in samples fermented by BY-01+LGG ${ }^{\circledR}$ after 21 days of storage. In fermented soy samples, the presence of LGG $^{\circledR}$ showed no significant differences in lactic acid production (Graph A, Figure 1). The highest value was $0.52 \%$ in samples fermented with YF-L01 after seven days of storage. Similar TA values were reported by Mishra et.al. in 2019 [67] in fermented soy blends and by Kpodo et al. in fermented soy-peanut blends [68]. In coconut samples (Graph C, Figure 1), LGG ${ }^{\circledR}$ only had an effect in day 14 and 21, where the samples showed significantly higher lactic acid content. The highest value was $0.48 \%$, found in samples fermented by BY-01+LGG ${ }^{\circledR}$ after 14 days of storage.

\subsubsection{Viability of BB- $12^{\circledR}$ and LGG ${ }^{\circledR}$ during Storage}

The growth of BB-12 ${ }^{\circledR}$ and LGG ${ }^{\circledR}$ was evaluated through their viable cell count during storage. According to the results that are shown in Figure 2, all of the substrates were suitable for the growth of both probiotic strains. BB-12 ${ }^{\circledR}$ CFU ranged from $1.8 \times 10^{7}$ to $3.2 \times 10^{8} \log$ CFU $/ g$ (Graph A, Figure 2). This values are in line with the results that were obtained by Pavunc et al., who reported BB-12 ${ }^{\circledR}$ growth to be higher than $10^{6} \mathrm{CFU} / \mathrm{g}$ in fermented cereal matrices [69].

A
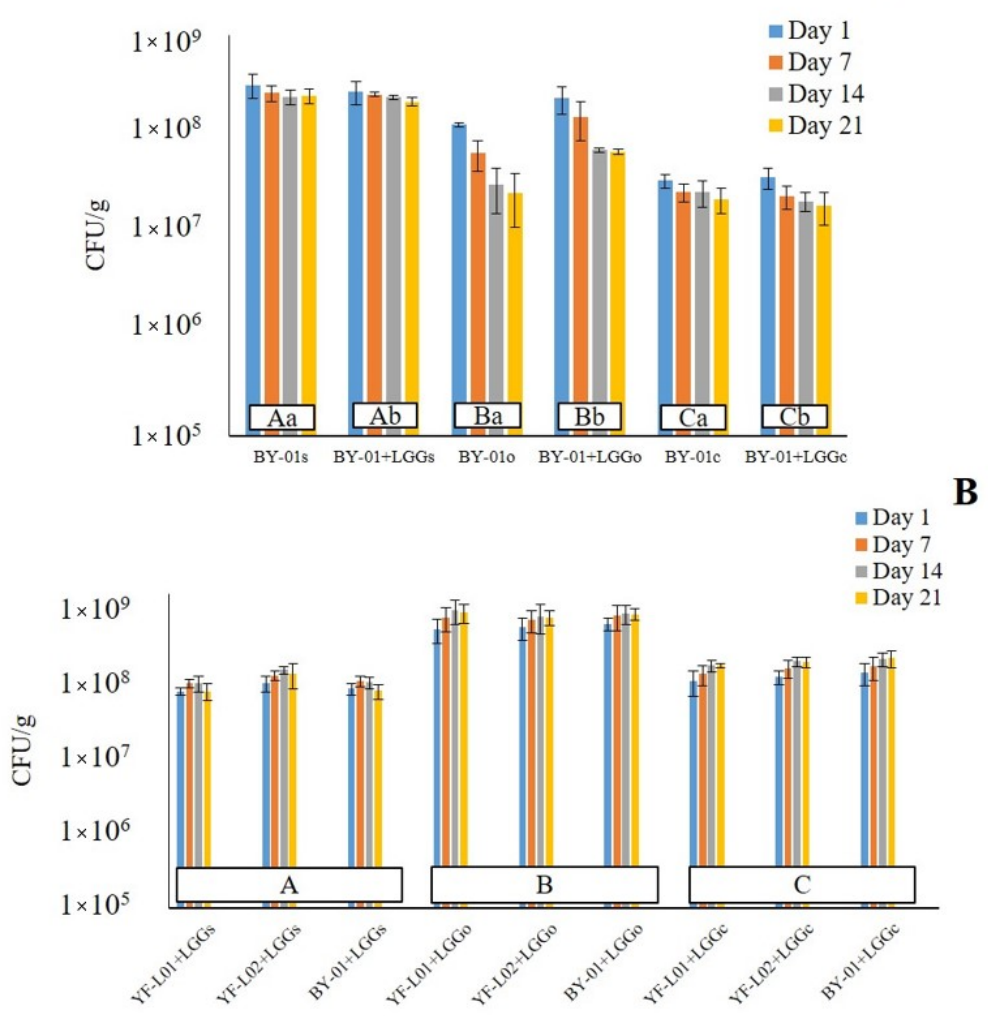

Figure 2. Viable cell counts of (A) BB-12 ${ }^{\circledR}$ and (B) LGG ${ }^{\circledR}$ in fermented (s) soy, (o) oat, and (c) coconut bases in day $1,7,14$, and 21 of storage at $6{ }^{\circ} \mathrm{C}$. ${ }^{A B C}$ Means with different uppercase superscripts indicate significant differences between different bases $(p<0.05) .{ }^{a b}$ Means with different lowercase superscripts indicate significant differences between different culture combinations $(p<0.05)$. Because no significant difference between different cultures in each base was observed in the case of LGG ${ }^{\circledR}$ CFU, only uppercase superscripts are shown. 
There was a significant interaction between the base and the storage time as well as the culture combination. This indicates that different BB- $12^{\circledR}$ CFU values at different time points or fermented with different cultures depend on the fermented base. BB-12 $₫ C F U$ were significantly different in the three bases. Highest values were reported in soy, followed by oat and lastly coconut. A reasonable explanation for this would be that Bifidobacterium was able to metabolize sucrose and GOSs [70], which are present in the soy base, while it was not capable of degrading starch, the main carbon source in the oat base. The viable cell count of BB-12 ${ }^{\circledR}$ was significantly improved when BY- 01 was combined with LGG ${ }^{\circledR}$ only in oat samples. It was also observed that BB-12 ${ }^{\circledR}$ growth decreased over storage time. In fermented soy and coconut samples, LGG ${ }^{\circledR}$ did not have any significant effect on BB-12 ${ }^{\circledR}$ growth.

Regarding LGG ${ }^{\circledR}$ viable cell count (Graph B, Figure 2), CFU values ranged from $5.7 \times 10^{7}$ to $6.2 \times 10^{8} \log \mathrm{CFU} / \mathrm{g}$. These values correlate to the ones previously found in fermented cereal bases [66] and legume bases [53]. The only significant interaction was between the base and the storage time. This indicates that different LGG ${ }^{\circledR}$ CFU at different time points depends on the fermented base. LGG $^{\circledR}$ growth in oat samples was significantly different to soy and coconut. A reasonable explanation may be LGG $^{\circledR}$ 's preference for simple carbohydrates [71]. Carbohydrate content in oat was higher than in the other two bases [1]. Thus, LGG ${ }^{\circledR}$ has access to a greater amount of sugars that can use as carbon source. YF-L01, YF-L02, and BY-01 did not show any significant difference between them when combined with LGG ${ }^{\circledR}$, which indicates that none of them affected the growth of LGG ${ }^{\circledR}$. The only exception was the sample that was fermented by YF-L02+LGG ${ }^{\circledR}$ in soy samples, whose LGG ${ }^{\circledR}$ CFU were higher in comparison to the other two combinations in day 14 and 21.

All fermented samples showed BB-12 ${ }^{\circledR}$ and LGG ${ }^{\circledR}$ CFU values above $10^{7} \mathrm{CFU} / \mathrm{g}$. This would suggest both strains as good candidates for probiotic plant-based alternatives to dairy.

\subsection{Rheological Behavior}

Figure 3 shows the flow curves of fermented soy, oat, and coconut samples. The shape of all flow curves was the same among different culture combinations. Therefore, one flow curve per fermented base was reported.

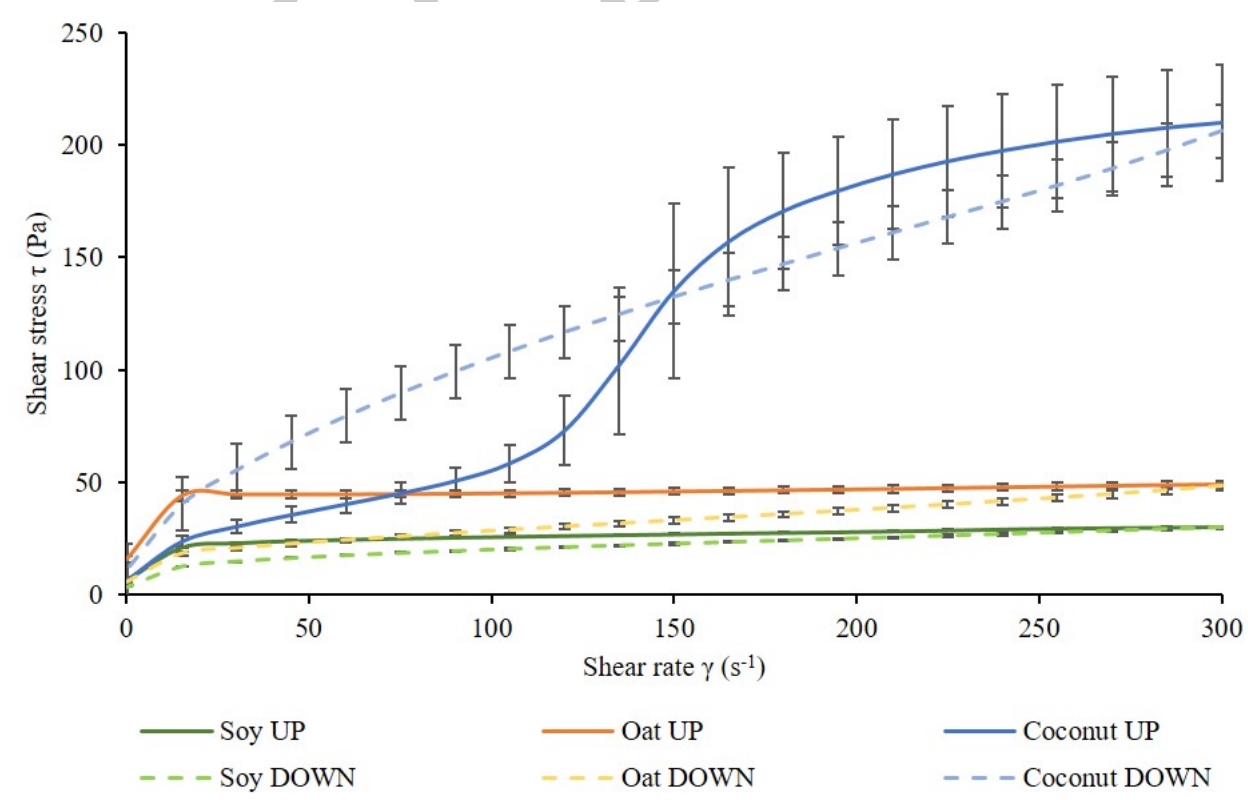

Figure 3. Flow curves under controlled shear rates from 0 to $300 \mathrm{~s}^{-1}$ and from 300 to $0 \mathrm{~s}^{-1}$ of fermented soy, oat, and coconut samples. Continuous lines correspond to up-flow and discontinuous lines to down-flow. 
Literature supports that fermented soy-based beverages [72], oat-based preparations [4], and coconut yogurts [73] experience shear thinning. Nevertheless, the flow test revealed shear thinning in fermented soy and oat samples, which was already reflected in previous studies $[8,58,74]$, but unexpected behavior in fermented coconut samples. The microstructure in each of the plant bases was expected to be different from each other, due to the very different components. Therefore, different flow behavior and different shear stress values were expected. A regular hysteresis loop was observed in fermented soy and oat samples, typical of dairy fermented products. In contrast, fermented coconut flow curves had an atypical S-shape in comparison to those reported in previous studies with coconut yogurt [75] and significantly higher shear stress values in comparison to the other two bases. Large crystal particles may have formed in these fermented samples due to the high fat content in coconut milk [14]. Fat crystals form a three-dimensional structure that confer resistance to deformation [76] until the yield value is exceeded. After that, the material behaves like a viscous fluid [77]. A shear thickening behavior was observed in fermented coconut samples up to $100 \mathrm{~s}^{-1}$, which could be attributed to dominating starch structure. At higher shear rates, a shear thinning behavior was observed, indicating a potential breakdown of the starch and a predominant effect of the crystal.

All of the shear stress values of fermented soy, oat, and coconut at a shear rate of $45.2 \mathrm{~s}^{-1}$ were evaluated (Table 6). There was no significant interaction between the effect of the base and the effect of the culture in fermented soy and oat samples. No significant differences between the culture combinations were found in any of the fermented bases, but all fermented bases were significantly different from each other.

Table 6. Shear stress and complex modulus of fermented soy, oat, and coconut samples at a controlled shear rate of $42.5 \mathrm{~s}^{-1}$ and an oscillatory frequency of $1.52 \mathrm{~Hz}$, respectively

\begin{tabular}{ccc}
\hline Base & $\boldsymbol{\tau} \mathbf{( P a )}$ & $\left.\mathbf{G}^{*} \mathbf{( P a}\right)$ \\
\hline Soy & $24.1 \pm 0.3^{A}$ & $170.1 \pm 3.3^{A}$ \\
Oat & $44.8 \pm 1.7^{C}$ & $471.7 \pm 40.9^{C}$ \\
Coconut & $35.8 \pm 3.5^{B}$ & $232.9 \pm 69.4^{B}$ \\
\hline
\end{tabular}

$A B C$ Means with different uppercase superscripts in the same column indicate significant differences between different bases $(p<0.05)$.

Oat shear stress values at $45.2 \mathrm{~s}^{-1}$ shear rate were significantly higher. A reasonable explanation could be the higher protein content in oats in combination with their starch, which may be responsible for a higher viscosity. A firmer structure could have been formed from $\beta$-glucans already present in oat [33]. $\beta$-glucans have a high water-holding capacity, which could have enhanced gel strength. Their gelling properties can increase viscosity in liquid solutions [32]. $\quad \beta$-glucans can form a polysaccharide-protein matrix where fat droplets are held [32]. Another type of polysaccharides that contributes to improving the textural and rheological properties of fermented foods are EPS. Girard et al. concluded that dairy gels containing EPS reduced gelation time in comparison to those without EPS, especially when the polysaccharides had a high net negative charge [78]. Bernat et al. concluded that strains with EPS-producing capacity could increase viscosity [79] and, therefore, reduce shear thinning behavior [80]. Consequently, the presence of EPS could confer stability to the structure of fermented samples. The LGG ${ }^{\circledR}$ strain is not the only EPS-producing strain used in this study. Stijepic et al. noted the ability to produce EPS of S. thermophilus [81]. Moreover, Martensson et al. observed EPS produced by L. delbrueckii subsp. bulgaricus in oats [57], and Salazar et al. demonstrated EPS-producing ability of different Lactobacillus and Bifidobacteria strains [82]. Therefore, further studies would be needed to precisely determine the origin of EPS present in the samples of this study, since its production cannot only be attributed to LGG ${ }^{\circledR}$. However, high LGG ${ }^{\circledR}$ cell count was observed in fermented oat samples, which may confirm the previous hypothesis about its ability to produce EPS. Soy protein can aggregate at its isoelectric point ( $\mathrm{pH}$ 4.5) [26], forming a gel network that contains other matrix components, such as lipids and carbohydrates. Their high water absorption capacity can fortify the gel-like structure and, therefore, increase the viscosity of fermented soy samples [10]. Nevertheless, 
soy samples in this study showed lower shear stress values than the other two bases and, therefore, lower viscosity. This indicates weaker gel structures in fermented soy samples. Grygorczyk reported that the composition and processing of soy proteins may affect gelation properties [83]. If glycinin (11S) content is higher than $\beta$-conglycinin (7S), the gel will have higher deformability when the stress is applied, since the former has better gel-forming properties than the latter. Given the obtained results, soy proteins in the samples could have lower $11 \mathrm{~S}$ content than $7 \mathrm{~S}$. The different culture combinations did not have any significant effect in any of the bases. These results indicate that the addition of LGG ${ }^{\circledR}$ did not have any negative effect in the flow behavior of any of the samples.

The hysteresis area of fermented soy and oat samples represents the structural recovery during shear and it is shown in Table 7. It was not possible to calculate hysteresis area for coconut samples, since the obtained loop was not regular, as can be seen in Figure 3. Therefore, it was removed from the results. However, Aboulfazli et al. reported high viscosity of fermented coconut milk samples, higher firmness, and higher hysteresis areas in comparison to soy and dairy samples [84]. Larger hysteresis loop areas reflect higher energy amounts that are needed to deform internal structural network and therefore, firmer structures [76]. Smaller hysteresis areas reflect higher ability to recover the structure when shear rate is reduced. Soy samples fermented with YF-L01+LGG ${ }^{\circledR}$ showed higher hysteresis area values than those fermented with YF-L01. This indicates that $\mathrm{LGG}^{\circledR}$ in combination with YF-L01 could increase viscosity of fermented soy samples. Oat samples did not show any significant differences between culture combinations. Therefore, LGG ${ }^{\circledR}$ did not have any effect on their structural recovery. Brückner et al. reported partial recovery of high protein fermented oat samples, relating the high solid contents to a faster rearrangement of the microstructure [85].

Table 7. Hysteresis loop area of fermented soy and oat samples.

\begin{tabular}{ccc}
\hline \multirow{2}{*}{ Culture Combination } & \multicolumn{2}{c}{ Base } \\
\cline { 2 - 3 } & Soy & Oat \\
\hline YF-L01 & $1239.6 \pm 83.8^{a}$ & $3849 \pm 110.1$ \\
YF-L02 & $1286 \pm 43^{a b}$ & $3693.5 \pm 71.8$ \\
BY-01 & $1275.7 \pm 39.6^{a b}$ & $4505.4 \pm 63.2$ \\
YF-L01+LGG ${ }^{\circledR}$ & $1357.4 \pm 58.8^{b}$ & $4019.7 \pm 317$ \\
YF-L02+LGG ${ }^{\circledR}$ & $1327.6 \pm 75.3^{a b}$ & $4015.5 \pm 104.5$ \\
BY-01+LGG ${ }^{\circledR}$ & $1346.1 \pm 72.5^{a b}$ & $3987.3 \pm 466$ \\
\hline
\end{tabular}

${ }^{a b}$ Means in the same column with different lowercase superscripts indicate significant differences between different culture combinations $(p<0.05)$.

An oscillation test was performed to evaluate the viscoelastic properties of fermented soy, oat, and coconut. Storage modulus $\left(\mathrm{G}^{\prime}\right)$ and loss modulus $\left(\mathrm{G}^{\prime \prime}\right)$ determine the elastic and viscous components of all fermented bases, respectively, and are shown in Figure 4. The graphical representation of the data shows that $G^{\prime}$ and $G^{\prime \prime}$ increased with progressively increasing frequency in all bases. All samples showed higher $G^{\prime}$ values than $G^{\prime \prime}$ for all culture combinations, revealing a gel-like rheological behavior. Donkor et al. reported similar $\mathrm{G}^{\prime}$ values for fermented soy milk with probiotic cultures [21]. Brückner-Gühman et al. stated that, in fermented oat samples, protein aggregates, starch granules, and fat droplets increase the rigidity of the gel [85]. This could explain high $G^{\prime}$ values in fermented oat samples in this study, which were significantly higher than those reported by Brückner-Gühman et al. [85]. They also concluded that the main contributor to the stability of an oat concentrate gel would be the swollen starch instead of an oat protein network. $G^{*}$ indicates the firmness of the samples and it was chosen to compare all three bases (Table 6). It comprises $G^{\prime}$ and $G^{\prime \prime}$, and it represents the overall resistance to deformation [86]. $G^{*}$ values of fermented soy, oat, and coconut were significantly different from each other. Oat samples reported higher complex modulus. Different culture combinations did not have any significant effect in $G^{*}$ in any of the bases, which indicates no significant effect of LGG ${ }^{\circledR}$ in complex modulus. 


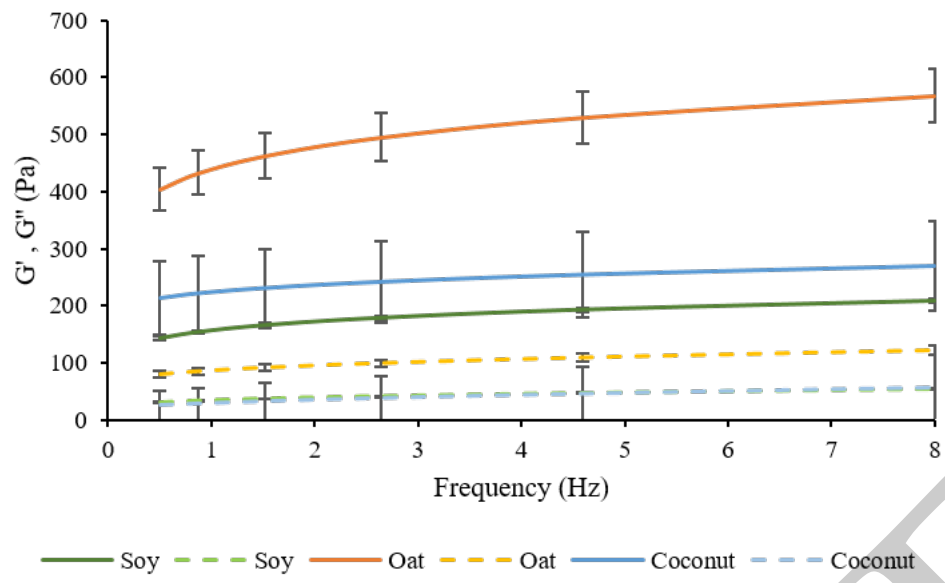

Figure 4. Dynamic mechanical spectra in frequency sweeps of fermented soy, oat, and coconut samples.

Continuous lines correspond to $\mathrm{G}^{\prime}$, discontinuous lines correspond to $\mathrm{G}^{\prime \prime}$.

For a greater understanding of the textural properties of the fermented samples, up-flow shear stress and complex modulus were correlated with evaluated textural attributes in each sample (Tables 8 and 9). A combination of sensory perception and physical measurements allows a more precise characterization of the food material. The correlations were clearly different across bases, which emphasizes different behavior of the different microstructures in each fermented base. In soy samples, only the perception of gel firmness and mouth thickness showed a positive correlation with the shear stress. However, it did not occur along the entire flow, but only at specific shear rates. Mouth thickness was positively correlated to shear stress at the end of the flow. This could be explained by the ability to recover its structure after the shear rate is applied, which was already observed in fermented dairy [87]. Fermented soy complex modulus was strongly correlated to gel firmness, showing that $G^{*}$ at increasing frequencies enhanced the perception of this attribute. Shear stress in fermented oat samples was positively correlated with gel firmness along the entire flow curve and with mouth coating and smoothness at the beginning of the up-flow curve. This is supported by the findings of Buldo et al [87]. Nevertheless, $G^{*}$ of fermented oat samples was positively correlated with gel firmness, but negatively correlated with mouth coating and smoothness perception. The firmer the sample, and the higher $\mathrm{G}^{*}$, the less product remains in the palate when it is swallowed. In coconut samples, gel firmness, mouth thickness, and mouth coating showed remarkable positive correlation with shear stress and with the complex modulus. The more fat crystals are produced, the higher the elastic modulus will be and, therefore, the harder and firmer the sample will be perceived [10]. Consequently, when shear stress and $G^{*}$ increase, the perception of these attributes will be enhanced. These results encourage further investigation on rheological behavior of fermented plant-bases with this relatively novel approach, where the perception of textural attributes is correlated to experimental measurements. 
Table 8. Correlation coefficient between up-flow and textural attributes identified in each fermented base.

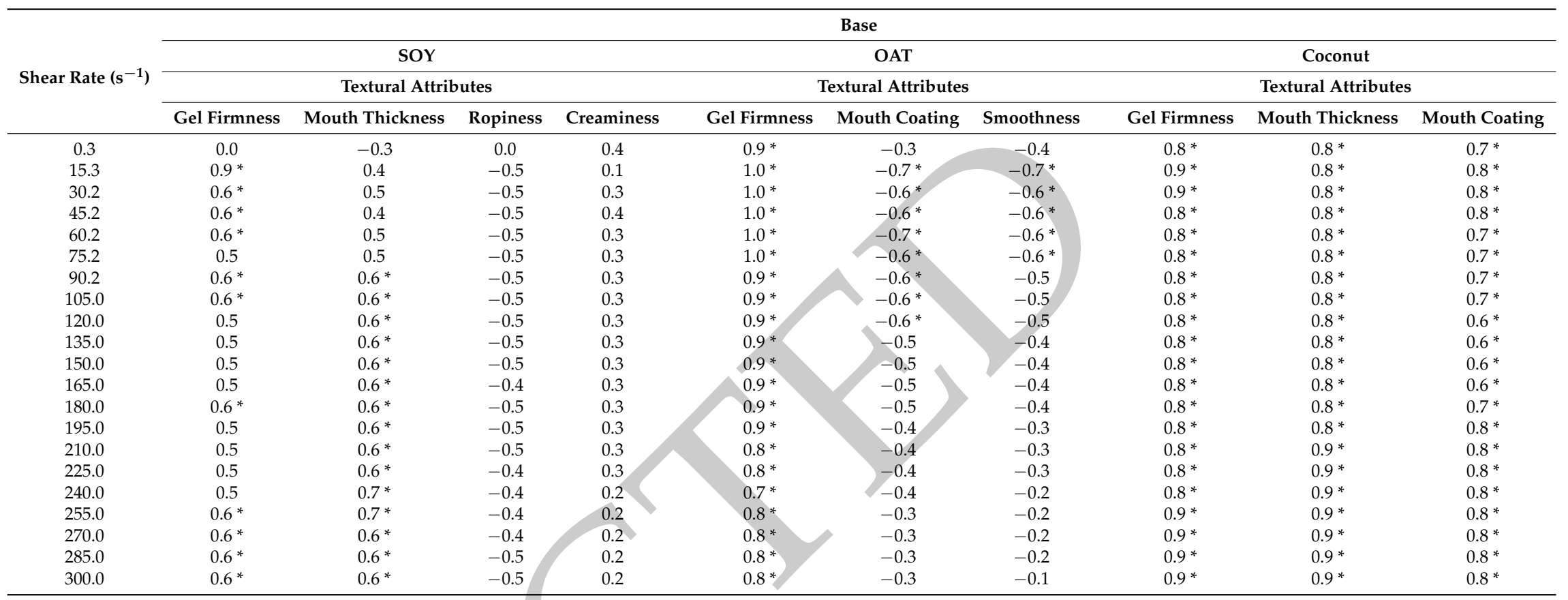

${ }^{*}$ Asterisk denotes significant correlation between rheological parameter and textural attribute (value between $0.6-1$ and $(-0.6)-(-1)$ ).

Table 9. Correlation coefficients between $G^{*}$ and textural attributes identified in each fermented base.

\begin{tabular}{|c|c|c|c|c|c|c|c|c|c|c|}
\hline \multirow{4}{*}{ Shear Rate $\left(s^{-1}\right)$} & \multicolumn{10}{|c|}{ Base } \\
\hline & \multicolumn{4}{|c|}{ SOY } & \multicolumn{3}{|c|}{ OAT } & \multicolumn{3}{|c|}{ Coconut } \\
\hline & \multicolumn{4}{|c|}{ Textural Attributes } & \multicolumn{3}{|c|}{ Textural Attributes } & \multicolumn{3}{|c|}{ Textural Attributes } \\
\hline & Gel Firmness & Mouth Thickness & Ropiness & Creaminess & Gel Firmness & Mouth Coating & Smoothness & Gel Firmness & Mouth Thickness & Mouth Coating \\
\hline 0.9 & $0.8 *$ & 0.3 & -0.5 & 0.3 & 0.9 * & $-0.7^{*}$ & $-0.7^{*}$ & 0.9 * & $0.8 *$ & 0.9 * \\
\hline 1.5 & $0.8^{*}$ & 0.3 & -0.5 & 0.3 & $0.9 *$ & -0.7 * & -0.7 * & $0.9 *$ & $0.8^{*}$ & $0.9^{*}$ \\
\hline 2.6 & $00 *$ & 0.3 & -0.5 & 0.3 & 0.9 * & $-0.8^{*}$ & $-0.7^{*}$ & $0.9^{*}$ & $0.8^{*}$ & 0.9 * \\
\hline 4.6 & $0.9^{*}$ & 0.2 & -0.5 & 0.3 & $0.9 *$ & $-0.8^{*}$ & $-0.7^{*}$ & $0.9 *$ & $0.8^{*}$ & $0.9 *$ \\
\hline 8.0 & $0.8^{*}$ & 0.0 & -0.4 & 0.3 & 0.9 * & $-0.8^{*}$ & $-0.8^{*}$ & $0.9 *$ & 0.8 * & 0.9 * \\
\hline
\end{tabular}

* Asterisk denotes significant correlation between rheological parameter and textural attribute (value between $0.6-1$ and $(-0.6)-(-1)$ ). 


\subsection{Carbohydrates and Acids in Fermented Samples}

The carbohydrate levels identified in fermented samples (Table 10) were directly correlated to acid levels (Table 11). Acids were produced when carbohydrates were consumed. The results of oat samples fermented with culture combinations containing LGG ${ }^{\circledR}$ were not reliable and, therefore, not included in the comparison. However, part of the carbohydrates present in these samples prior to fermentation were consumed, since they became acid after fermentation and during storage time. Therefore, the performance of LGG ${ }^{\circledR}$-containing culture combinations in oat can be assumed as satisfactory, since they were able to acidify and also intensify some sensory attributes (described below). Oat samples were the ones containing more carbohydrates and the ones with smaller amounts of sucrose. Moreover, they were the only ones that had glucose and in high amounts. Additionally, fructose content was higher than in soy and coconut samples. Maltose was also detected only in oat samples. A reasonable explanation would be that it was a product from oat starch degradation. In fermented soy samples, $9.5 \%$ of the total sucrose content was metabolized in comparison to the unfermented sample, producing a small amount of fructose. Previous studies already identified sucrose, fructose, and glucose in fermented soy milk with mixed cultures of Bifidobacterium [88]. However, only sucrose and fructose were found in soy samples in this study. This occurred because the strains utilized the glucose resulting from sucrose breakdown. There were no differences between the culture combinations, since all of the samples showed the same levels of carbohydrates. Coconut samples were the only ones containing different amounts of sucrose between the different culture combinations. However, they were not significantly different. Fructose was identified in low quantities in all samples fermented without LGG $^{\circledR}$ and in those that were fermented with YF-L01+LGG ${ }^{\circledR}$. Although the differences between all samples were not significant, this could reflect inability to ferment sucrose of $L_{G G}{ }^{\circledR}$, which was also reported by Meurman et al. [89]. However, more recent studies proved the ability of L. rhamnosus GG to ferment this carbohydrate [90].

Acetic acid, hexanoic acid, octanoic acid, and decanoic acid are the main organic acids that have been attributed to vinegary, pungent, and rancid flavor in yogurt [91]. The presence of these compounds could negatively influence the sensory perception of fermented plant-based products [68]. However, only acetic acid was identified in the samples that were fermented in this study. Lactic acid was the only acid found in all samples of all three bases. Fermented soy samples presented lactic acid and acetic acid, the main products of carbohydrate metabolism of LAB and bifidobacteria [19]. However, acetic acid was only found in soy samples fermented with culture combinations containing LGG $^{\circledR}$ and in equal amounts. The ability of $\mathrm{LGG}^{\circledR}$ to produce acetic acid through fermentation of legume substrates was already shown by Petruláková and Valík [53]. Lactic acid content did not vary across the different culture combinations. In fermented oat samples, no differences in acids content were observed among the different culture combinations. The lactic acid content significantly increased after fermentation due to metabolization of sugars and, also, small amounts of acetic acid were produced. In fermented coconut samples, lactic, acetic, and citric acid were identified in different amounts. LGG ${ }^{\circledR}$ significantly increased the amount of detected lactic acid when it was combined with YF-L01 and with BY-01. Acetic acid and citric acid content was not significantly different among all fermented coconut samples. Malic acid was identified in samples fermented without LGG ${ }^{\circledR}$ in the culture and in unfermented samples. An explanation could be that LGG ${ }^{\circledR}$ performed malolactic fermentation, completely degrading malic acid that is present in the initial sample [92]. 
Table 10. Carbohydrates identified in fermented soy, oat, and coconut samples.

\begin{tabular}{|c|c|c|c|c|c|}
\hline Base & Culture Combination & Glucose & Fructose & Sucrose & Maltose \\
\hline \multirow{7}{*}{ Soy } & YF-L01 & 0.00 & 0.74 & 50.55 & 0.00 \\
\hline & YF-L02 & 0.00 & 0.74 & 50.55 & 0.00 \\
\hline & BY-01 & 0.00 & 0.74 & 50.55 & 0.00 \\
\hline & YF-L01+LGG ${ }^{\circledR}$ & 0.00 & 0.74 & 50.55 & 0.00 \\
\hline & YF-L02+LGG ${ }^{\circledR}$ & 0.00 & 0.74 & 50.55 & 0.00 \\
\hline & BY-01+ LGG ${ }^{\circledR}$ & 0.00 & 0.74 & 50.55 & 0.00 \\
\hline & Unfermented soy & 0.00 & 0.00 & 55.81 & 0.00 \\
\hline \multirow{4}{*}{ Oat } & YF-L01 & 92.38 & 4.06 & 4.34 & 24.15 \\
\hline & YF-L02 & 92.38 & 4.06 & 4.34 & 24.15 \\
\hline & BY-01 & 92.38 & 4.06 & 4.34 & 24.15 \\
\hline & Unfermented oat & 94.55 & 3.93 & 5.77 & 24.08 \\
\hline \multirow{7}{*}{ Coconut } & YF-L01 & $<\mathrm{LOD}$ & 1.50 & 48.35 & $<\mathrm{LOD}$ \\
\hline & YF-L02 & $<\mathrm{LOD}$ & 1.35 & 47.45 & $<\mathrm{LOD}$ \\
\hline & BY-01 & $<\mathrm{LOD}$ & 1.65 & 49.05 & $<\mathrm{LOD}$ \\
\hline & YF-L01+LGG ${ }^{\circledR}$ & $<\mathrm{LOD}$ & 1.20 & 47.40 & $<\mathrm{LOD}$ \\
\hline & YF-L02+LGG ${ }^{\circledR}$ & 0.60 & 0.55 & 47.70 & $<$ LOD \\
\hline & BY-01+LGG ${ }^{\circledR}$ & $<\mathrm{LOD}$ & 0.60 & 48.25 & $<\mathrm{LOD}$ \\
\hline & Unfermented coconut & 0.27 & 1.13 & 27.64 & 0.00 \\
\hline
\end{tabular}

Table 11. Acids identified in fermented soy, oat, and coconut samples.

\begin{tabular}{|c|c|c|c|c|c|c|}
\hline Base & Culture Combination & Lactic Acid & Acetic Acid & Tartaric Acid & Citric Acid & Malic Acid \\
\hline \multirow{7}{*}{ Soy } & YF-L01 & 3.50 & $0.00^{a}$ & 3.50 & 0.00 & 0.00 \\
\hline & YF-L02 & 3.50 & $0.00^{a}$ & 3.50 & 0.00 & 0.00 \\
\hline & BY-01 & 3.50 & $0.00^{a}$ & 3.50 & 0.00 & 0.00 \\
\hline & YF-L01+LGG ${ }^{\circledR}$ & 3.50 & $2.00^{b}$ & 3.50 & 0.00 & 0.00 \\
\hline & YF-L02+LGG ${ }^{\circledR}$ & 3.50 & $2.00^{b}$ & 3.50 & 0.00 & 0.00 \\
\hline & BY-01+LGG ${ }^{\circledR}$ & 3.50 & $2.00^{b}$ & 3.50 & 0.00 & 0.00 \\
\hline & Unfermented soy & 0.10 & 0.00 & 0.00 & 0.85 & 0.00 \\
\hline \multirow{4}{*}{ Oat } & YF-L01 & 3.40 & 0.10 & 0.00 & 0.18 & 0.05 \\
\hline & YF-L02 & 3.40 & 0.10 & 0.00 & 0.18 & 0.05 \\
\hline & BY-01 & & 0.10 & 0.00 & 0.18 & 0.05 \\
\hline & Unfermented oat & 0.03 & 0.00 & 0.00 & 0.22 & 0.27 \\
\hline \multirow{7}{*}{ Coconut } & YF-L01 & 2.90 & $0.25^{a}$ & $<\mathrm{LOD}$ & 0.30 & 1.55 \\
\hline & YF-L02 & 3.25 & $0.25^{a}$ & $<\mathrm{LOD}$ & 0.25 & 1.00 \\
\hline & BY-01 & 2.80 & $0.50^{b}$ & $<\mathrm{LOD}$ & 0.30 & 1.45 \\
\hline & YF-L01+LGG ${ }^{\circledR}$ & 4.25 & $0.25^{a}$ & $<\mathrm{LOD}$ & 0.30 & $<\mathrm{LOD}$ \\
\hline & YF-L02+LGG ${ }^{\circledR}$ & 4.50 & $0.25^{a}$ & $<\mathrm{LOD}$ & 0.30 & $<\mathrm{LOD}$ \\
\hline & BY-01+LGG ${ }^{\circledR}$ & 4.35 & $0.50^{b}$ & $<\mathrm{LOD}$ & 0.30 & $<\mathrm{LOD}$ \\
\hline & Unfermented coconut & 0.15 & 0.15 & 0.0 & 0.47 & 1.89 \\
\hline
\end{tabular}

Contents are measured in mg of compound per gram of sample. ${ }^{a b}$ Means in the same column inside each base with different lowercase superscripts indicate significant differences between different culture combinations $(p<0.05)$.

\subsection{Volatile Organic Compounds}

The obtained results were classified in two categories to evaluate the presence of VOCs and the effect of fermentation with and without LGG $^{\circledR}$ : major contributors to fermented dairy flavor and characteristic VOCs of each of the fermented raw materials. This was done to observe potential increase of dairy flavor and reduction of off-flavors of the plant-based raw materials, respectively. 


\subsubsection{Major Contributors to Fermented Dairy Flavor}

The targeted VOCs were those that were related to dairy flavor. Fermented soy, oat, and coconut bases were screened for their presence by FID and the results are shown in Table 12. When all fermented bases were compared, diacetyl, acetoin, acetaldehyde, acetone, and ethanol levels were significantly different in all three bases. Ethyl acetate, an ester that is found in lactobacilli fermented products [93] and in dairy cheese [94], was targeted but not identified in any of them.

Table 12. Targeted Volatile Organic Compounds (VOCs) identified by FID in fermented soy, oat, and coconut samples.

\begin{tabular}{|c|c|c|c|c|c|c|c|}
\hline Base & Culture Combination & Acetaldehyde & Diacetyl & Acetoin & Acetone & 3-Methyl-Butanal & Ethanol \\
\hline \multirow{5}{*}{ Soy } & YF-L01 & $2.73 \pm 0.06^{\text {Ade }}$ & $4.05 \pm 0.17^{A b}$ & $15.38 \pm 0.13^{A b c}$ & $1.47 \pm 0.02^{A a b}$ & $\mathrm{n} / \mathrm{s}$ & $0.71 \pm 0.09 A a$ \\
\hline & YF-L02 & $2.52 \pm 0.08^{A d}$ & $7.06 \pm 0.48^{A c}$ & $13.51 \pm 1.11 \mathrm{Aab}$ & $1.48 \pm 0.08^{A a b}$ & $\mathrm{n} / \mathrm{s}$ & $2.08 \pm 0.04 \mathrm{Aab}$ \\
\hline & BY-01 & $2.84 \pm 0.01 \mathrm{Ae}$ & $3.54 \pm 0.02 A a b$ & $9.39 \pm 1.68 \mathrm{Aa}$ & $1.55 \pm 0.04^{A b}$ & & \\
\hline & YF-L02 + LGG ${ }^{\circledR}$ & $0.58 \pm 0.02^{A a}$ & $3.89 \pm 0.15^{A a b}$ & $26.24 \pm 0.4^{A d}$ & $1.54^{A b}$ & $\mathrm{n} / \mathrm{s}$ & $2.59 \pm 0.02 A b$ \\
\hline & BY-01 + LGG ${ }^{\circledR}$ & $1.77 \pm 0.08^{A c}$ & $2.98 \pm 0.2^{A a}$ & $18.79 \pm 1.54{ }^{A c}$ & $1.65 \pm 0.08^{A b}$ & & $5.55 \pm 0.3^{A d}$ \\
\hline \multirow{5}{*}{ Oat } & YF-L01 & $1.08 \pm^{B b}$ & $4.27 \pm 0.02^{B a}$ & $40.19 \pm 0.7^{B a}$ & $0.3 \pm 0.05^{B}$ & $1.21 \pm 0.04^{c}$ & $92.8 \pm 3.18^{B d}$ \\
\hline & BY-01 & $2.53 \pm 0.06^{B c}$ & $8.34 \pm 0.09^{B b}$ & $41.89 \pm 3.31^{B a}$ & $0.35 \pm 0.01^{B}$ & $0.1 \pm 0.11^{a b}$ & $8.15 \pm 2.33^{B a}$ \\
\hline & YF-L01 + LGG ${ }^{\circledR}$ & $0.25^{B a}$ & $16.7 \pm 0.01^{B c d}$ & $97.86 \pm 0.55^{B c}$ & $0.27 \pm 0.03^{B}$ & $0.29 \pm 0.01^{b}$ & $24.54 \pm 0.65^{B c}$ \\
\hline & YF-L02 + LGG ${ }^{\circledR}$ & $0.22 \pm 0.01^{B a}$ & $17.53 \pm 0.07^{B d}$ & $81.41 \pm 3.05^{B b}$ & $0.32 \pm 0.09^{B}$ & $0.15^{a b}$ & $18.28 \pm 0.25^{B b c}$ \\
\hline & BY-01 + LGG ${ }^{\circledR}$ & $0.29 \pm 0.03^{B a}$ & $15.74 \pm 0.07^{B c}$ & $87.57 \pm 2.01^{B b}$ & $0.29 \pm 0.02^{B}$ & $0.06^{a}$ & $16.8 \pm 0.36^{B b}$ \\
\hline \multirow{2}{*}{ Coconut } & YF-L01 & $3.42 \pm 0.03^{C a}$ & $3.27 \pm 0.05^{\mathrm{Ca}}$ & $50.5 \pm 0.34^{C b}$ & $0.42 \pm 0.03^{C}$ & $\mathrm{n} / \mathrm{s}$ & $71.32 \pm 1.61^{C}$ \\
\hline & YF-L02 & $3.1 \pm 0.03^{C b}$ & $18.23 \pm 0.09 \mathrm{Cd}$ & $48.19 \pm 1.02 \mathrm{Cab}$ & $0.44 \pm 0.06^{C}$ & $\mathrm{n} / \mathrm{s}$ & $71.81 \pm 0.12^{C}$ \\
\hline
\end{tabular}

${ }_{A B C}$ Means in the same column with different uppercase superscripts indicate significant differences between different bases $(p<0.05)$. ${ }^{a b c d}$ Means in the same column inside each base with different lowercase superscripts indicate significant differences between different culture combinations $(p<0.05)$.

Diacetyl, acetoin, and acetaldehyde play a key role in dairy flavor perception [95] and are products of pyruvate degradation. Pyruvate can be metabolized through two main pathways. The first one converts pyruvate into $\alpha$-acetolactate, which is decarboxylated to diacetyl in aerobic conditions without any enzymatic activity. Diacetyl can then be reduced to acetoin and acetoin to 2-3-butanediol. The second one transforms pyruvate into acetaldehyde through acetyl-coenzyme A (acetyl-CoA) [96]. The effect LGG ${ }^{\circledR}$ can cause on the levels of these pyruvate breakdown products can be relevant for the sensory perception of fermented samples. Acetoin and diacetyl provide buttery odors that are responsible for caramel and sweet flavors, respectively [49]. Acetoin is generally produced in higher amounts than diacetyl through citrate metabolism, which was reflected in all three fermented bases. Both compounds were significantly higher in fermented oat samples, followed by coconut and soy. This could be explained by a higher fermentable carbohydrate content in oat samples. Citrate levels in the plant bases was unknown; therefore, it was not possible to confirm that a higher citrate content in oat base was responsible for these results. LGG $^{\circledR}$-containing samples reflected higher acetoin levels in all three bases in comparison to samples that were fermented with culture combinations without $L G G^{\circledR}$. Consequently, it could be assumed that LGG $^{\circledR}$ has a high diacetyl-reductase activity to transform diacetyl into acetoin. Acetoin was produced in lower quantities in soy samples by BY-01+LGG ${ }^{\circledR}$ and YF-L01+LGG ${ }^{\circledR}$ in comparison to YF-L02+LGG ${ }^{\circledR}$. LGG ${ }^{\circledR}$ increased diacetyl levels in oat and coconut when it was combined with YF-L01 and BY-01. In contrast, it decreased them in combination with YF-L02 in all three bases. Kaneko et al. reported a relationship between excessive amounts of diacetyl and unpleasant odors [96]. This suggests that YF-L02 without LGG ${ }^{\circledR}$ would not be an appropriate candidate to ferment oat samples due to the high diacetyl levels that were identified in this sample. One of the main principal components of fermentation aroma in yoghurt is acetaldehyde [96]. Samples that were fermented with LGG $^{\circledR}$-containing culture combinations showed significantly lower acetaldehyde content in all three bases. This could be due to a low ability 
of L. rhamnosus to produce it from carbohydrate, protein or nucleic acid sources, or due to a high enzymatic activity to convert it into ethanol. Acetaldehyde is a product of pyruvate degradation by acetyl-coenzyme A, but it can also be produced through other metabolic pathways from citrate by $S$. thermophilus (strain present in YF-L01, YF-L02, and BY-01). Acetone content was significantly higher in soy samples. It is a compound that confers apple and solvent flavor and has been identified in dairy products such as kefir [93]. Previous studies reported its presence in fermented soy and considered it another main contributor to flavor and aroma in yogurt [97]. LGG ${ }^{\circledR}$ did not show any significant effect on its production in any of the three bases. Ethanol levels were significantly higher in coconut samples, but the different culture combinations did not have a significant effect on its content. In contrast, LGG ${ }^{\circledR}$ significantly affected its production in certain fermented oat samples, more precisely reducing ethanol levels when it was combined with YF-L01 but increasing them when it was combined with BY-01. Kpodo et. al. detected ethanol in their fermented matrix containing peanut and soy but not in their dairy yogurt control [68]. They attributed its presence to glucose breakdown and amino acids catabolism. Nevertheless, they remarked that it is not a relevant contributor to dairy flavor profiles but probably a complementary one. Ethanol can also react with free fatty acids and be further converted into ethyl esters, which would provide floral and fruity odors [49]. 3-methylbutanal was found in all fermented oat samples and in non-significant amounts in the other two fermented bases. Yan Chun et al. identified it in soy milk, although it had a low flavor dilution factor and, therefore, was not considered a major flavor component [98]. This compound derives from an enzymatic reaction of isoleucine and leucine [99] and has been already identified in oat samples by Salmenkallio-Marttila [100] and by Lee et al. [101] as a product of amino acid degradation by L. paracasei. Natrella et al. characterized it as the most relevant volatile compound in mozzarella cheese, providing nutty and fresh cheese odor [102]. Dan et al. reported higher 3-methylbutanal content when dairy milk was fermented by a mixed culture of L. bulgaricus and S. thermophilus when the rates of the latter one were higher [103]. This supports the results of this study, where oat samples fermented with YF-L01 without LGG ${ }^{\circledR}$ (pure S. thermophilus) reflected higher levels of 3-methylbutanal than the one fermented with YF-L01+LGG ${ }^{\circledR}$. 1-Butanol was not identified in soy samples and only found in very low amounts in some of the fermented oat and coconut samples, therefore it was not reported in Table 12.

\subsubsection{Characteristic VOCs of Soy, Oat, and Coconut}

A total of 54 untargeted volatile compounds were identified by GC-MS in all three fermented bases. They comprised ketones, esters, acids, aldehydes, alcohol, furans, sulfurs, lactones, terpenes, benzenes, and aromatic compounds. 12 of them (ethyl acetate, 2,3-pentanedione, hexanal, ethyl decanoate, $\alpha$-pinene, benzaldehyde, 3 -carene, acetoin, $\delta$-decalactone, $\gamma$-octalactone, dimethyl disulfide, and 2-heptanone) were present in the three fermented bases. Some compounds, such as acetone and diacetyl, were identified by FID and also detected by GC-MS, two methods based on different detection principles. Previous studies were taken as references for predominant volatiles of soy $[98,104,105]$, oat $[40,101]$, and coconut $[106,107]$. The identification of compounds in this study was compared to their results. Two compounds were present in all three fermented samples, namely hexanal and benzaldehyde. Hexanal is mainly produced through linoleic acid oxidation and it can be further oxidized to hexanoic acid and reduced to 1-hexanol by dehydrogenase enzymes during fermentation processes [101]. Since linoleic acid is the primary fatty acid in oat [101] and soybeans [92], detection of hexanal in fermented soy and oat samples was expected in this study. Hexanal content was significantly higher in these two fermented bases in comparison to fermented coconut samples, where it was found in very low quantities, as previous studies suggested [107]. No significant effect of the different culture combinations was found in any of the bases, which indicates that LGG $^{\circledR}$ did not have any effect on its production. Achouri et al. detected its presence in soy milk and in soy blends and observed changes in its levels during storage, attributing them to further lipid oxidation [104]. Hexanal is associated with green and beany odors [105], but also related to rancidity [41]. Nevertheless, Sides et al. stated that, since hexanal is present in oat samples with acceptable flavors, perception of rancidity is not directly 
linked to the presence of hexanal but to its concentration [108]. Regarding benzaldehyde, a compound found in Camembert cheese [109], it was significantly higher in fermented oat samples, followed by coconut and soy samples. Achouri et al. and Kaczmarska et al. reported its presence in soy milk products and in germinated soy, but stated its minor contribution to soybean aroma $[104,105]$. Salmenkallio [100], McGorrin [40], and Lee [101] detected the presence of benzaldehyde in uncooked and cooked oatmeal and attributed it to an almond odor. Its presence could be associated with reducing sugars and amino acids interactions [108]. Wang et al. identified benzaldehyde in coconut milk [110], and fermented coconut samples in this study were the only ones showing significantly different benzaldehyde content between the different culture combinations (Table 12). However, LGG ${ }^{\circledR}$ had no significant effect on benzaldehyde production.

The main contributors to soy flavor (in addition to hexanal and benzaldehyde) are nonanal, heptanal, octanal, acetic acid, 1-hexanol, 1-pentanol, 1-octen-3-ol, heptanol, 2-pentyl furan, 2-ethyl furan, 1-octen-3-one [98,104,105]. From this list, only hexanal and benzaldehyde were identified in fermented soy samples in this study, and none of the different culture combinations had an effect on their quantity. Nevertheless, other volatile compounds were found in fermented soy samples, and those whose production was affected by LGG ${ }^{\circledR}$ are shown in Table 13. 2-heptanone is a product of octanoic acid metabolism and it was detected in low amounts in fermented soy samples, which is aligned with the results from Ahmad et al. [111]. They found this compound in soy cheese and also in Cheddar cheese. Vazquez et al. associated it with milk off-flavor [112], but literature highlights its main role in blue cheeses [113]. 2,3-Pentanedione is considered a dairy yogurt flavor contributor [91] and was detected in high levels in fermented soy samples, in line with the findings of Kaneko et al. [96] and Ahmad et al. [111]. Ethyl octanoate and ethyl decanoate were detected in all fermented soy samples. Ahmad et al. found both compounds in cheddar cheese but only the former in soy cheese [111]. They also identified lactones in dairy cheese but not in soy cheese. In contrast, fermented soy samples in this study contained $\delta$-decalactone and $\delta$-octalactone in different quantities. This would be a positive aspect of soy fermentation with the culture combinations used in this study for dairy alternatives. When LGG ${ }^{\circledR}$ was combined with YF-L02, the content of 2-heptanone, ethyl octanoate, ethyl decanoate, limonene, $\delta$-decalactone, 2-methyl-butan, and 2-pentyl-furan significantly decreased. When it was combined with B1-01, 2-heptanone, 2-3-pentanedione, ethyl octanoate, ethyl decanoate, 2-methyl butanal, $\delta$-decalactone, and $\delta$-octalactone levels significantly decreased. When LGG $^{\circledR}$ was combined with YF-L01, limonene content decreased, but 2-pentyl-furan content increased.

Table 13. Untargeted VOCs in fermented soy samples in which different culture combinations had an effect.

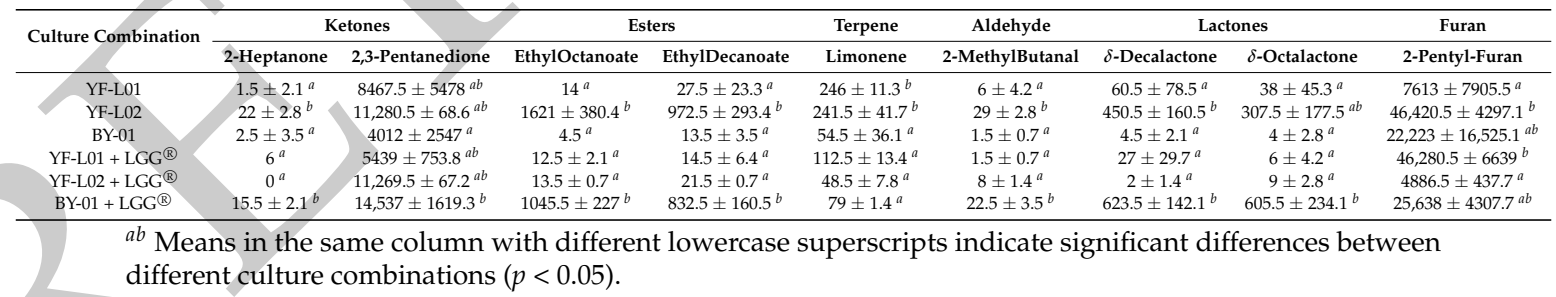
different culture combinations $(p<0.05)$.

According to McGorrin [40] and Lee et al. [101], the key volatile compounds of oat flavor are hexanal, nonanal, benzaldehyde, 3- methyl-butanal, octanal, 1-hexanol, 1-pentanol, 1-octen-3-ol, 3-methyl-1-butanol, 2-ethylfuran, 2- heptanone, 3-hydroxy-2-butanone, and 3,5-octadien-2-one. However, only hexanal, benzaldehyde, 3-methyl-butanal, octanal, 2-ethyl-furan, and 1-hexanol were found in fermented oat samples of this study. Previous literature reported variations in volatile compounds with fermentation time in oats [101]. Initial fermentation stages were associated with aldehydes and later stages with acids, alcohols, ketones, and furans. Table 14 shows VOCs in whose content LGG ${ }^{\circledR}$ had a significant effect. 2-3-Pentanedione was previously identified in oats [114] and it is one of the main flavor components of fermented dairy milk [19]. Its presence in fermented oat 
samples in higher levels than in fermented soy and coconut samples may suggest oat's potential for fermented dairy alternatives. However, 2-3-Pentanedione levels decreased when the culture combination contained LGG ${ }^{\circledR}$. Although previous studies did not find ethyl acetate in dairy yogurt, Beshkova et. al detected its presence in kefir [93] and it was also found in the fermented oat samples in this study. Lee et al. identified nonanal, hexanal, 2-pentylfuran, 1-octen-3-ol, and 2-nonenal as lipid degradation products [101]. They observed that hexanal content decreased during fermentation of oats while 1-hexanol levels increased. This could explain the presence of the latter compound in fermented oat samples. Toluene, ethanol, acetone, and 2-propanol were the VOCs that were found in higher amounts in fermented oat. Toluene did not vary among culture combinations and, therefore, was not reported in the table, but it has been found in dairy yogurts [91] and also in fermented oat [115]. Acetone levels, previously identified by FID, drastically decreased when YF-L01 was combined with LGG $^{\circledR}$, as well as the content of 2-propanol and ethanol. When YF-L02 was supplemented with LGG ${ }^{\circledR}$, 2-3-pentanedione and limonene levels decreased. The combination of BY-01 with LGG ${ }^{\circledR}$ increased the content of 2-methyl-3-thiolanone and ethyl acetate, but decreased the amount of 2-3-pentanedione and furfural.

Table 14. Untargeted VOCs in fermented oat samples in which different culture combinations had an effect.

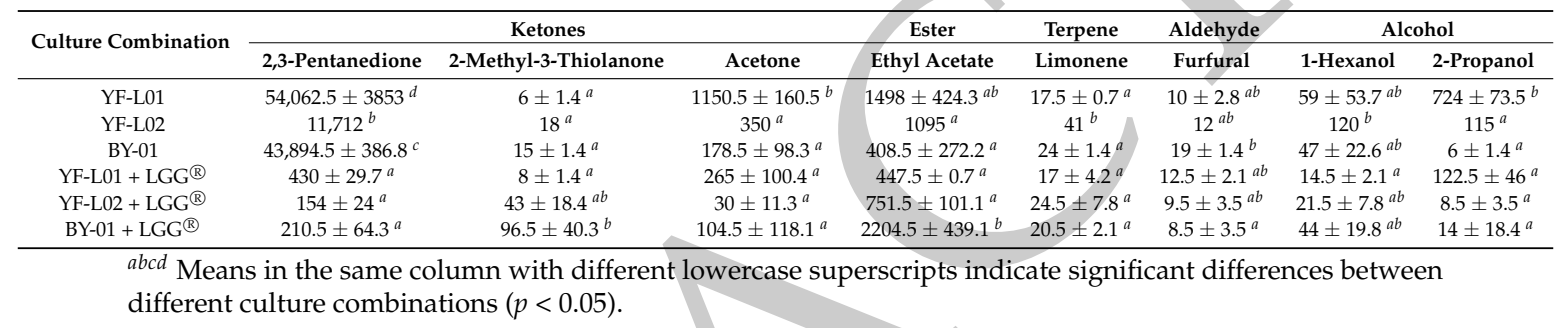

Borse et al. and Santos et al. highlighted hexanal, 2-heptanone, nonanal, acetic acid, 2-ethylfuran, 2-pentanone, ethyl lactate, ethyl acetate, $\delta$-octalactone, $\delta$-decalactone, dodecanoic acid, octanoic acid, 1-hexanol, phenyl ethyl alcohol, 2-methyl tetrahydrofuran, tetradecanone, hexadecanone, ethyl octanoate, ethyl acetate, ethyl decanoate, as predominant compounds of coconut flavor [106,107]. From all of them, only the first ten compounds were identified in coconut samples in this study. Although the different culture combinations did not have any significant effect on its production, GC-MS results revealed the presence of ethyl acetate in fermented coconut samples, in higher amounts than in the other two fermented bases. Santos et al. had previously attributed its presence to a nutty aroma [107]. Ethyl lactate, previously characterized as the main flavor component in coconut variety neera [106], was detected in all samples. Furthermore, phenylacetaldehyde was also found in all samples in low levels. It is a derivative compound from phenyl ethyl alcohol, another key aroma contributor in coconut [106], which would explain its presence. $\delta$-octalactone and $\delta$-decalactone were also present in all fermented coconut samples, together with butyrolactone. This was expected since they are major contributors to coconut flavor derived from hydroxy acids [116]. Table 15 shows the untargeted VOCs in fermented coconut samples whose content was affected by LGG ${ }^{\circledR}$. LGG $^{\circledR}$ increased the content of 2-pentanone and decreased the content of 2-3-pentanedione when it was combined with YF-L01. In combination with YF-L02, LGG ${ }^{\circledR}$ increased 2-pentanone and $\alpha$-pinene production, but decreased that of 2-3-pentanedione. When BY-01 was supplemented with LGG ${ }^{\circledR}, 2$-pentanone, diacetyl, $\gamma$-nonalactone, butyrolactone, and 1-butanol contents increased while 2-3-pentanedione levels decreased. In relation to diacetyl levels detected by FID, culture combinations produced significantly different amounts according to the results obtained by GC-MS. When BY-01 was supplemented with LGG ${ }^{\circledR}$, diacetyl content was higher than when it was on its own. These results concur with the findings of De Souza-Oliveira et al. They reported a synergy between S. thermophilus and L. rhamnosus, where diacetyl production was higher in co-culture fermentation than with the pure cultures [117]. 
Table 15. Untargeted VOCs in fermented coconut samples in which different culture combinations had an effect.

\begin{tabular}{|c|c|c|c|c|c|c|c|}
\hline \multirow{2}{*}{ Culture Combination } & \multicolumn{3}{|c|}{ Ketone } & \multirow{2}{*}{$\begin{array}{c}\text { Terpene } \\
\alpha \text {-Pinene }\end{array}$} & \multicolumn{2}{|c|}{ Lactone } & \multirow{2}{*}{$\begin{array}{c}\text { Alcohol } \\
\text { 1-Butanol }\end{array}$} \\
\hline & 2-Pentanone & 2-3-Pentanedione & Diacetyl & & $\gamma$-Nonalactone & Butyrolactone & \\
\hline YF-L01 & $10.5 \pm 0.7^{a}$ & $89 \pm 9.9^{c}$ & $11,375.5 \pm 675.3^{a}$ & $77.5 \pm 12^{b c}$ & $2153 \pm 144.2^{a b}$ & $12.5 \pm 2.1^{a b}$ & $45.5 \pm 7.8^{a b}$ \\
\hline YF-L02 & $8.5 \pm 0.7^{a}$ & $65.5 \pm 3.5^{b}$ & $49,102 \pm 5395.2^{b}$ & $64 \pm 2.8^{a b}$ & $1883.5 \pm 156.3^{a b}$ & $12 \pm 2.8^{a b}$ & $43.5 \pm 2.1^{a b}$ \\
\hline YF-L01+LGG ${ }^{\circledR}$ & $26.5 \pm 4.9^{b}$ & $23.5 \pm 4.9^{a}$ & $32,402.5 \pm 5052.3^{a b}$ & $69.5 \pm 2.1^{a b c}$ & $2211.5 \pm 266.6^{b}$ & $18 \pm 2.8^{b c}$ & $45.5 \pm 5.7^{a b}$ \\
\hline YF-L02+LGG ${ }^{\circledR}$ & $28.5 \pm 11.3^{b c}$ & $17.5 \pm 1.4^{a}$ & $47,037.5 \pm 1850.5^{b}$ & $86.5 \pm 16.3^{c}$ & $2403.5 \pm 84.9^{b}$ & $22 \pm 4.9^{c}$ & $55 \pm 7.8^{b}$ \\
\hline BY-01+LGG ${ }^{\circledR}$ & $39 \pm 2.8^{c}$ & $15 \pm 1.4^{a}$ & $39,865 \pm 1390.2^{b}$ & $66 \pm 1.4^{a b c}$ & $2153 \pm 257.4^{a b}$ & $13.5 \pm 0.7^{a b}$ & $39.5 \pm 0.7^{a b}$ \\
\hline
\end{tabular}

\subsection{Sensory Perception of Fermented Soy, Oat, and Coconut Samples}

The trained panel identified and evaluated different sensory attributes for each of the fermented soy, oat, and coconut samples. The sensory scores for each fermented base are presented in three spider diagrams (Figure 5). Each diagram enables to observe the effect of each culture combination on the perception of each attribute.
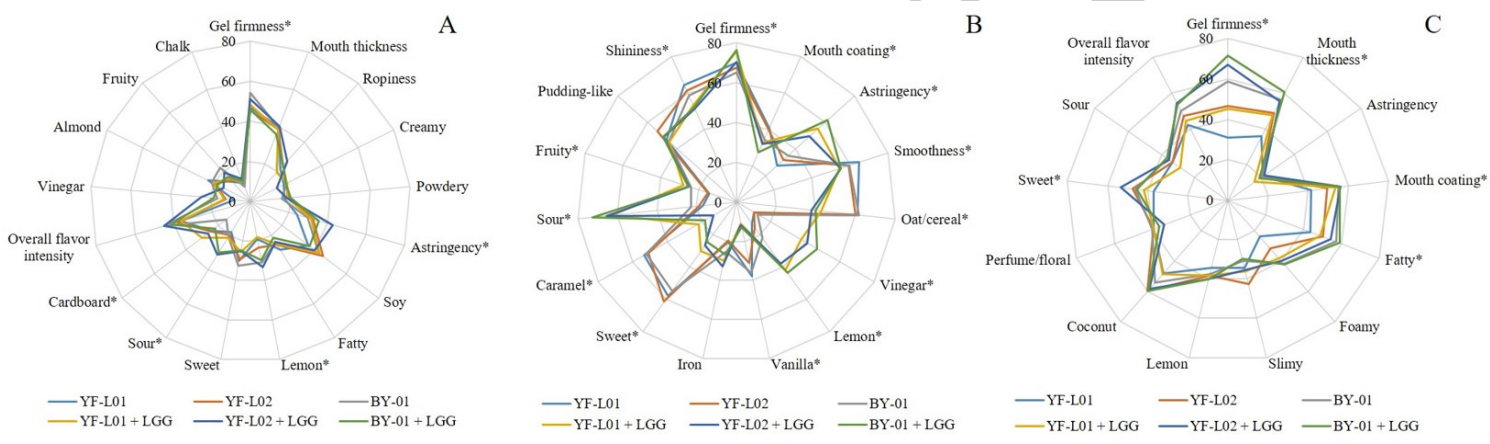

Figure 5. Perception of sensory attributes in (A) soy, (B) oat, and (C) coconut samples fermented with different culture combinations.

Certain attributes were evaluated in all three bases and therefore its perception was compared across them. Gel firmness was strongly perceived in oat samples, which could be attributed to a stronger structure formed by gelatinized oat starch and other non-starch polysaccharides. This result is supported by the rheology data reported above. Notwithstanding the unidentified effect of LGG ${ }^{\circledR}$ on flow properties of the samples, its presence affected sensorial perception of certain textural attributes. The astringency perception was higher in fermented soy and oat samples in comparison to fermented coconut samples. This attribute is related to dryer and rougher raw materials, such as the former ones. Different perception of astringency is attributed to the fat content in coconut samples, which may have smoothened the mouthfeel in comparison to the other two materials. Additionally, polyphenols present in soy and oat could enhance astringency perception. Sweet, lemon, and sour taste were identified in all three bases, but no significant difference was reported between them. Food materials prone to coalescence enhance the perception of fat in mouth [118], which is supported by the obtained results in this study. Coconut samples scored higher in fatty perception than soy, due to their high fat content. The presence of homogenized fat globules contributes to mouth coating and thickness perception [83]. In fermented soy samples, significant differences across samples were observed in the perception of gel firmness, astringency, sourness, lemon taste, and cardboard. The results suggested a potential effect of $\mathrm{LGG}^{\circledR}$ in the perception of some attributes. Nevertheless, the base contributed to a great extent to the flavor perception, not only in fermented soy, but also in fermented oat and coconut. When it was combined with BY-01, LGG ${ }^{\circledR}$ increased sourness perception and decreased gel firmness perception in fermented soy samples. In combination with YF-L02, astringency, sourness and lemon taste increased. In fermented oat samples, gel firmness, astringency, sweetness, sourness, lemon, 
fruity, vinegar, oat/cereal, caramel, vanilla flavor, as well as shininess, smoothness, and mouth coating showed significant differences in their perception across samples. Differences in sensory perception in samples fermented with and without LGG ${ }^{\circledR}$ were appreciated. Gel firmness, astringency, vinegar, lemon taste, fruity taste, and sourness perception was higher in samples fermented with LGG ${ }^{\circledR}$ in the culture combination. This correlates to the results observed in previous experiments. Oat samples that were fermented with culture combinations containing LGG ${ }^{\circledR}$ were the ones that acidified the most and these enhanced attributes are linked to acid foods. Mouth coating, smoothness, shininess, sweetness, oat/cereal, vanilla, and caramel taste perception were lower in these samples. Thus, it can be suggested that the presence of LGG ${ }^{\circledR}$ further acidified the samples. Although the acid content of LGG ${ }^{\circledR}$-containing oat samples could not be used for the statistical analyses, the results of the titratable acidity experiment indicated that these samples contained higher lactic acid content, which supports this hypothesis. In coconut samples, perception of gel firmness, mouth coating, mouth thickness, sweetness, and fatness showed significant differences across samples. All samples containing LGG ${ }^{\mathbb{R}}$ were perceived as firmer in comparison to the ones fermented without LGG ${ }^{\circledR}$. In combination with YF-L01, LGG ${ }^{\circledR}$ increased mouth thickness and mouth coating. Perfume odor was specifically evaluated in coconut samples. Esterification of free fatty acids in coconut with ethanol, which was higher than in soy and oat samples, may have generated ethyl esters with floral odors [49]. However, no significant difference was found in its perception across the different samples.

\subsection{Correlation of Instrumental Measurements with Flavor Perception}

PCA was conducted to reduce the dimensionality of the data and identify patterns based on the correlation between VOCs and the perception of flavor attributes in each fermented sample (Figure 6).

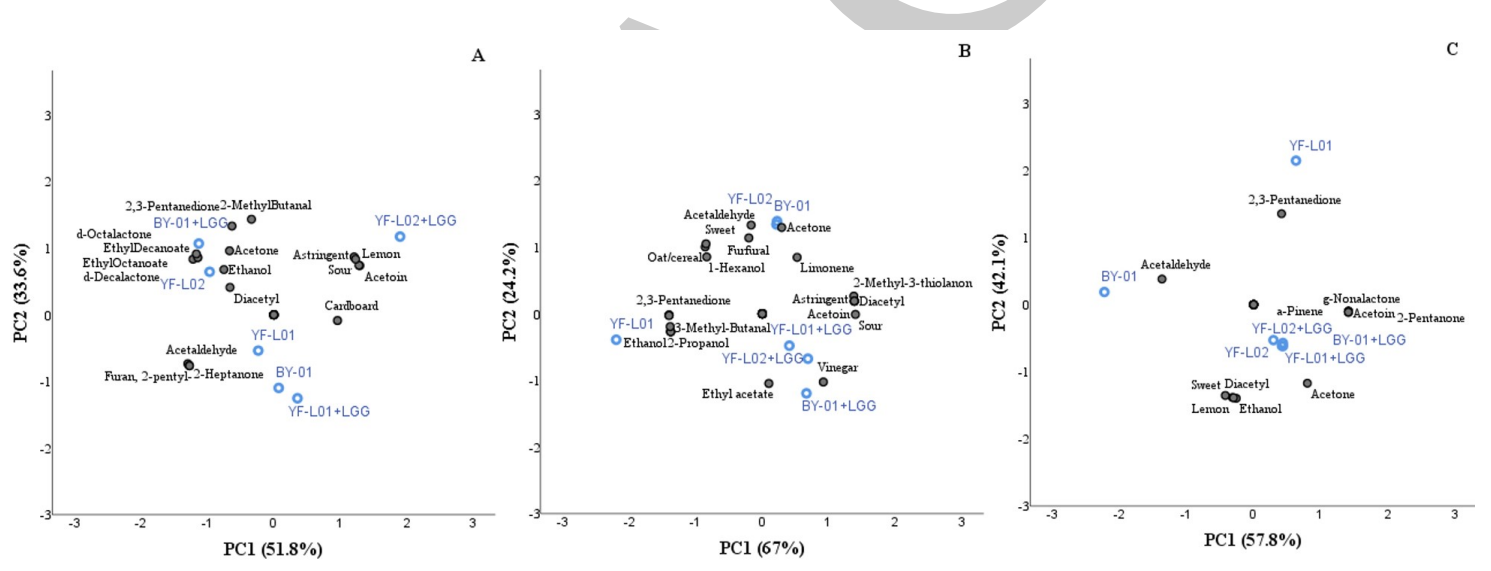

Figure 6. Effect of different culture combinations and the VOCs they produced on the sensory perception of flavor attributes. PCA bi-plot of the first two principal components (PCs) in fermented (A) soy, (B) oat, and (C) coconut samples labeled by culture combinations.

PCA of fermented soy samples explains $85.4 \%$ of the total variance, comprising $51.8 \%$ of the first PC and $33.6 \%$ of the second PC. The presence of acetoin correlated positively with the perception of lemon taste, astringency and sourness $(R=0.9)$. This was attributed to samples that were fermented with YF-L02+LGG ${ }^{\circledR}$, which is supported by the FID results reported above. Samples that were fermented with YF-L02 were located in an opposite area of the graph to YF-L02+LGG ${ }^{\circledR}$ along PC1 axis. Therefore, an effect of LGG ${ }^{\circledR}$ when combined with YF-L02 on the perception of these flavor attributes was indicated by this analysis. In contrast, acetaldehyde, 2-pentylfuran, and 2-heptanone were positively correlated $(R=0.9)$ with each other but negatively correlated with the three flavor attributes mentioned above $(R=-0.9)$. This would suggest that the presence of these volatiles was responsible for a less acidic taste. Samples fermented with YF-L01, BY-01, and YF-L01+LGG ${ }^{\circledR}$ clustered together around these components. This would suggest that $\mathrm{LGG}^{\circledR}$ did not have an effect on fermented soy flavor when combined with YF-L01, which is supported by the sensory results. 
PCA of fermented oat samples explained $91.4 \%$ of the total variance, comprising $67 \%$ of the first PC and $24.4 \%$ of the second PC. All culture combinations containing LGG $^{\circledR}$ clustered together far from their respective cultures without $L G G{ }^{\circledR}$, which indicated that $L G G^{\circledR}$ had an effect on fermented oat flavor. They were close to the attributes sourness, astringency, lemon and fruity flavors. A positive correlation between them and the presence of diacetyl, acetoin and 3-methyl-thiolanone $(R=0.9-1)$ was found. The sweetness and oat/cereal flavor were related with the presence of acetaldehyde $(R=0.7)$ and acetone $(\mathrm{R}=0.4-0.5)$, although the association was not significantly strong. Samples that were fermented with YF-L02 and BY-01 were located close to these components. YF-L01 was found close to ethanol and propanol and these compounds were negatively correlated to diacetyl and acetoin $(\mathrm{R}=-1)$, which is supported by the results obtained by FID. PCA of fermented coconut samples explained $99.9 \%$ of the total variance, comprising $57.8 \%$ of the first PC and $42.1 \%$ of the second PC. Lemon taste and sweetness were positively correlated $(R=0.9)$ and also with ethanol $(R=0.9)$ and diacetyl $(R=1)$. Acetoin, $\gamma$-nonalactone, $\alpha$-pinene, and 2-pentanone were also positively correlated $(\mathrm{R}=1)$ and located close to the previously mentioned components. The sample fermented with YF-L02 clustered with all culture combinations containing LGG ${ }^{\circledR}$ around the previously mentioned attributes. This indicates that $\mathrm{LGG}^{\circledR}$ did not have any effect on fermented coconut flavor when added to YF-L02. Nevertheless, an effect of LGG ${ }^{\circledR}$ in the perception of fermented coconut flavor when combined with YF-L01 and BY-01 was observed. The sample fermented with BY-01 was associated with acetaldehyde, which is supported by the results obtained by FID. It was negatively correlated with all components except from sweetness, although the correlation was not significant. The presence of 2,3-pentanedione was negatively correlated with the perception of sweetness and lemon taste $(R=0.9)$ and associated with YF-L01. This sample was the one that scored lower in lemon taste perception in the sensory evaluation.

\section{Conclusions}

The use of culture combinations containing LGG $^{\circledR}$ showed significant effects in fermented plant bases. Acidification time was improved with its presence in fermented soy and oat samples and also post-acidification and TA increased in the latter. $L G G{ }^{\circledR}$ and BB-12 ${ }^{\circledR}$ were able to grow in all three fermented bases above $10^{7} \mathrm{CFU} / \mathrm{g}$, which indicates that soy, oat, and coconut are suitable substrates for their proliferation. LGG $^{\circledR}$ did not have any significant effect on the rheological behavior of any of the fermented bases. However, it was shown that each raw material reacted significantly differently to the same shear rate and frequency. This reflects an important role of the base on the texture, since protein, fiber, and starch enable the formation of firmer structures. Supplementation with LGG ${ }^{\circledR}$ resulted in higher acetoin levels and lower acetaldehyde levels in all three bases. Diacetyl content was also enhanced in oat and coconut samples when LGG ${ }^{\circledR}$ was combined with YF-L01 and BY-01. Regarding sensory perception of fermented samples, major effects of LGG $^{\circledR}$ were observed in oat samples. LGG $^{\circledR}$ increased perception of acid-related flavor attributes and decreased sweetness and oat/cereal taste when inoculated in oat samples in combination of all initial cultures. LGG ${ }^{\circledR}$ increased the gel firmness perception in all fermented coconut samples. On this basis, the results of this study encourage future research on the potential of probiotic LAB for the improvement of physicochemical properties in plant-based products.

Author Contributions: Writing and editing, original draft preparation, data curation and analysis, software utilization and statistical analysis, C.M.; Conceptualization and validation, C.M., P.E.J. and P.B.; Methodology, resources and investigation, P.B.; Review and supervision, P.B. and P.E.J.; Funding acquisition, P.E.J. All authors have read and agreed to the published version of the manuscript.

Funding: This work was supported by the Novo Nordisk Foundation project NNF16OC0021832.

Acknowledgments: The authors would like to acknowledge Tina Hoegholm for producing and performing most of the experimental work on the studied samples. Martina Sokolowsky and all the sensory panel is acknowledged for performing the sensory evaluation. Asger Geppel, Raquel Fernandez, Angelika Semmler and Kristian Fog Nielsen are acknowledge for the biochemical analyses. All the colleagues from Fresh Dairy, Global Applications organization in Chr. Hansen A/S are acknowledged for valuable discussions. 
Conflicts of Interest: The authors declare no conflict of interest.

\section{References}

1. Paul, A.A.; Kumar, S.; Kumar, V.; Sharma, R. Milk Analog: Plant based alternatives to conventional milk, production, potential and health concerns. Crit. Rev. Food Sci. Nutr. 2019, 1-19. [CrossRef] [PubMed]

2. Tangyu, M.; Muller, J.; Bolten, C.J.; Wittmann, C. Fermentation of plant-based milk alternatives for improved flavour and nutritional value. Appl. Microbiol. Biotechnol. 2019, 9263-9275. [CrossRef] [PubMed]

3. Mäkinen, O.E.; Wanhalinna, V.; Zannini, E.; Arendt, E.K. Foods for Special Dietary Needs: Non-dairy Plant-based Milk Substitutes and Fermented Dairy-type Products. Crit. Rev. Food Sci. Nutr. 2016, 56, 339-349. [CrossRef]

4. Heenan, C.N.; Adams, M.C.; Hosken, R.W.; Fleet, G.H. Survival and sensory acceptability of probiotic microorganisms in a nonfermented frozen vegetarian dessert. LWT Food Sci. Technol. 2004, 37, 461-466. [CrossRef]

5. Saint-Eve, A.; Granada, P.; Legay, G.; Cuvelier, G.; Delarue, J. Consumer acceptance and sensory drivers of liking for high plant protein snacks. J. Sci. Food Agric. 2019, 99, 3983-3991. [CrossRef]

6. Marko, A.; Rakická, M.; Mikušová, L.; Valík, L.; Šturdík, E. Lactic acid Fermentation of Cereal Substrates in Nutritional Perspective. Int. J. Res. Chem. Environ. 2014, 4, 80-92.

7. Peschel, A.O.; Kazemi, S.; Liebichová, M.; Sarraf, S.C.M.; Aschemann-Witzel, J. Consumers' associative networks of plant-based food product communications. Food Qual. Prefer. 2019, 75, 145-156. [CrossRef]

8. Bernat, N.; Cháfer, M.; Chiralt, A.; González-Martínez, C. Probiotic fermented almond "milk" as an alternative to cow-milk yoghurt. Int. J. Food Stud. 2015, 4, 201-211. [CrossRef]

9. Szparaga, A.; Tabor, S.; Kocira, S.; Czerwińska, E.; Kuboń, M.; Płóciennik, B.; Findura, P. Survivability of probiotic bacteria in model systems of non-fermented and fermented coconut and hemp milks. Sustainability 2019, 11, 6093. [CrossRef]

10. Akin, Z.; Ozcan, T. Functional properties of fermented milk produced with plant proteins. LWT Food Sci. Technol. 2017, 86, 25-30. [CrossRef]

11. Kocková, M.; Valík, L. Development of new cereal-, pseudocereal-, and cereal-leguminous-based probiotic foods. Czech J. Food Sci. 2014, 32, 391-397. [CrossRef]

12. Mauro, C.S.I.; Garcia, S. Coconut milk beverage fermented by Lactobacillus reuteri: Optimization process and stability during refrigerated storage. J. Food Sci. Technol. 2019, 56, 854-864. [CrossRef] [PubMed]

13. Chalupa-krebzdak, S.; Long, C.J.; Bohrer, B.M. Nutrient density and nutritional value of milk and plant-based milk alternatives. Int. Dairy J. 2018, 87, 84-92. [CrossRef]

14. Belewu, M.A.; Belewu, K.Y. Comparative Physico-Chemical Evaluation of Tiger-nut, Soybean and Coconut Milk Sources. Int. J. Agric. Biol. 2007, 9, 785-787.

15. Mills, E.N.; Breiteneder, H. Food allergy and its relevance to industrial food proteins. Biotechnol. Adv. 2005, 23, 409-414. [CrossRef]

16. LeBlanc, J.G.; Garro, M.S.; Savoy De Giori, G. Effect of pH on Lactobacillus fermentum growth, raffinose removal, $\alpha$-galactosidase activity and fermentation products. Appl. Microbiol. Biotechnol. 2004, 65, 119-123. [CrossRef]

17. LeBlanc, J.G.; Ledue-Clier, F.; Bensaada, M.; De Giori, G.S.; Guerekobaya, T.; Sesma, F.; Juillard, V.; Rabot, S.; Piard, J.C. Ability of Lactobacillus fermentum to overcome host $\alpha$-galactosidase deficiency, as evidenced by reduction of hydrogen excretion in rats consuming soya $\alpha$-galacto-oligosaccharides. BMC Microbiol. 2008, 8, 1-9. [CrossRef]

18. Sumarna. Changes of raffinose and stachyose in soy milk fermentation by lactic acid bacteria from local fermented foods of Indonesian. Malays. J. Microbiol. 2008, 4, 26-34. [CrossRef]

19. Delgado, S.; Guadamuro, L.; Flórez, A.B.; Vázquez, L.; Mayo, B. Fermentation of commercial soy beverages with lactobacilli and bifidobacteria strains featuring high $\beta$-glucosidase activity. Innov. Food Sci. Emerg. Technol. 2019, 51, 148-155. [CrossRef]

20. Cruz Cansino, N. Efecto de la ultra alta presión de homogeneización en licuado de soja y su comportamiento en el desarrollo de un producto fermentado. Rev. Colomb. Biotecnol. 2009, 3, 179.

21. Donkor, O.N.; Henriksson, A.; Vasiljevic, T.; Shah, N.P. Rheological properties and sensory characteristics of set-type soy yogurt. J. Agric. Food Chem. 2007, 55, 9868-9876. [CrossRef] [PubMed] 
22. Monteiro, S.R.; Lopes-da Silva, J.A. Effect of the molecular weight of a neutral polysaccharide on soy protein gelation. Food Res. Int. 2017, 102, 14-24. [CrossRef] [PubMed]

23. Kohyama, K.; Nishinari, K. Rheological Studies on the Gelation Process of Soybean $7 S$ and $11 S$ Proteins in the Presence of Glucono- $\delta$-lactone. J. Agric. Food Chem. 1993, 41, 8-14. [CrossRef]

24. Li, C.; Wang, C.L.; Sun, Y.; Li, A.L.; Liu, F.; Meng, X.C. Microencapsulation of Lactobacillus rhamnosus GG by Transglutaminase Cross-Linked Soy Protein Isolate to Improve Survival in Simulated Gastrointestinal Conditions and Yoghurt. J. Food Sci. 2016, 81, M1726-M1734. [CrossRef] [PubMed]

25. Mishra, S.; Mishra, H.N. Effect of Synbiotic Interaction of Fructooligosaccharide and Probiotics on the Acidification Profile, Textural and Rheological Characteristics of Fermented Soy Milk. Food Bioprocess Technol. 2013, 6, 3166-3176. [CrossRef]

26. Hefnawy, H.T.M.; Ramadan, M.F. Physicochemical characteristics of soy protein isolate and fenugreek gum dispersed systems. J. Food Sci. Technol. 2011, 48, 371-377. [CrossRef]

27. Yang, M.; Li, L. Physicochemical, textural and sensory characteristics of probiotic soy yogurt prepared from germinated soybean. Food Technol. Biotechnol. 2010, 48, 490-496.

28. O'Toole, D.K. Soybean: Soy-Based Fermented Foods, 2nd ed.; Elsevier: Amsterdam, The Netherlands, 2015; Volume 3-4, pp. 124-133. [CrossRef]

29. Marazza, J.A.; Garro, M.S.; Savoy de Giori, G. Aglycone production by Lactobacillus rhamnosus CRL981 during soymilk fermentation. Food Microbiol. 2009, 26, 333-339. [CrossRef]

30. Biel, W.; Bobko, K.; Maciorowski, R. Chemical composition and nutritive value of husked and naked oats grain. J. Cereal Sci. 2009, 49, 413-418. [CrossRef]

31. Dong, J.L.; Yu, X.; Dong, L.E.; Shen, R.L. In vitro fermentation of oat $\beta$-glucan and hydrolysates by fecal microbiota and selected probiotic strains. J. Sci. Food Agric. 2017, 97, 4198-4203. [CrossRef]

32. Bernat, N.; Cháfer, M.A.; González Martinez, C.; Rodriguez-García, J.; Chiralt, A. Optimisation of oat milk formulation to obtain fermented derivatives by using probiotic Lactobacillus reuteri microorganisms. Food Sci. Technol. Int. 2013, 21, 145-157. [CrossRef] [PubMed]

33. Anttila, H.; Sontag-Strohm, T.; Salovaara, H. Viscosity of beta-glucan in oat products. Agric. Food Sci. 2004, 13, 80-87. [CrossRef]

34. Zeidan, A.A.; Poulsen, V.K.; Janzen, T.; Buldo, P.; Derkx, P.M.; Øregaard, G.; Neves, A.R. Polysaccharide production by lactic acid bacteria: From genes to industrial applications. FEMS Microbiol. Rev. 2017, 41, S168-S200. [CrossRef]

35. Peterson, D.M. Storage Proteins, 2nd ed.; AACC International, Inc.: Eagan, Minnesota, 2011; pp. $123-142$. [CrossRef]

36. Pedó, I.; Sgarbieri, V.C.; Gutkoski, L.C. Protein evaluation of four oat (Avena sativa L.) cultivars adapted for cultivation in the south of Brazil. Plant Foods Hum. Nutr. 1999, 53, 297-304. [CrossRef]

37. Ma, C.Y.; Harwalkar, V.R. Thermal Coagulation of Oat Globulin. Cereal Chem. 1987, 64, 212-218.

38. Sayar, S.; White, P.J. Oat Starch: Physicochemical Properties and Function, 2nd ed.; AACC International, Inc.: Eagan, Minnesota, 2011; pp. 109-122. [CrossRef]

39. Lehtinen, P.; Kaukovirta-Norja, A. Oat Lipids, Enzymes, and Quality, 2nd ed.; AACC International, Inc.: Eagan, Minnesota, 2011; pp. 143-155. [CrossRef]

40. McGorrin, R.J. Key Aroma Compounds in Oats and Oat Cereals. J. Agric. Food Chem. 2019, 67, 13778-13789. [CrossRef] [PubMed]

41. Zhou, M.; Robards, K.; Glennie-Holmes, M.; Helliwell, S. Oat Lipids. J. Am. Oil Chem. Soc. 1999, 76, $159-169$. [CrossRef]

42. Heiniö, R.L. Influence of Processing on the Flavour Formation of Oat and Rye; VTT Publications: Helsinki, Finland, 2003; pp. 5-72.

43. Parrish, C.R. Moo-ove Over, Cow's Milk: The Rise of Plant-Based Dairy Alternatives The Rise of Plant-Based Milks. Pract. Gastroenterol. 2018, XLII, 20-27.

44. Saranov, I.A.; Kuznetsov, I.A.; Kuznetsova, I.V.; Magomedov, G.O. Investigation of melting and crystallization processes of fat components of praline masses. Proc. Voronezh State Univ. Eng. Technol. 2018, 80, 323-327. [CrossRef]

45. Devi, A.; Khatkar, B. Thermo-Physical Properties of Fats and Oils. Int. J. Eng. Technocal Res. 2017, 7, 45. [CrossRef] 
46. Lakshmi, T.; Mary Pramela, A. Coconut milk kefir: Nutrient composition and assessment of microbial quality. Int. J. Food Sci. Nutr. 2018, 3, 1-4.

47. Johansen, E. Use of Natural Selection and Evolution to Develop New Starter Cultures for Fermented Foods. Annu. Rev. Food Sci. Technol. 2018, 9, 411-428. [CrossRef]

48. Wright, V.A.; Axelsson, L. Lactic Acid Bacteria: An Introduction. In Lactic Acid Bacteria: Microbiological and Functional Aspects, 4th ed.; Taylor \& Francis: London, UK 2012; pp. 1-16.

49. Coolbear, T.; Weimer, B.; Wilkinson, M.G. Lactic Acid Bacteria: Lactic Acid Bacteria in Flavor Development. In Encyclopedia of Dairy Sciences, 2nd ed.; Elsevier: Amsterdam, The Netherlands, 2011; pp. 160-165. [CrossRef]

50. Ikujenlola, A.V.; Adurotoye, E.A.; Adeniran, H.A. Chemical and Sensory Properties of Probioticated Drinks from Blends of African Yam Bean, Soybean and Coconut Milk Analogues. Acta Univ. Cibiniensis. Ser. E Food Technol. 2020, 23, 147-156. [CrossRef]

51. Park, S.Y.; Lee, D.K.; An, H.M.; Kim, J.R.; Kim, M.J.; Cha, M.K.; Lee, S.W.; Kim, S.O.; Choi, K.S.; Lee, K.O.; et al. Producing functional soy-based yogurt incubated with bifidobacterium longum spm1205 isolated from healthy adult koreans. Biotechnol. Biotechnol. Equip. 2012, 26, 2759-2764. [CrossRef]

52. Angelov, A.; Gotcheva, V.; Hristozova, T.; Gargova, S. Application of pure and mixed probiotic lactic acid bacteria and yeast cultures for oat fermentation. J. Sci. Food Agric. 2005, 2141, 2134-2141. [CrossRef]

53. Petruláková, M.; Valík, L. Evaluation of legumes as a substrate for probiotic strain Lactobacillus rhamnosus GG. Acta Aliment. 2015, 44, 268-275. [CrossRef]

54. Kocková, M.; Valík, L. Suitability of cereal porridges as substrate for probiotic strain Lactobacillus rhamnosus GG. Potravinarstvo 2013, 7, 22-27. [CrossRef]

55. Laneuville, S.I.; Turgeon, S.L. Microstructure and stability of skim milk acid gels containing an anionic bacterial exopolysaccharide and commercial polysaccharides. Int. Dairy J. 2014, 37, 5-15. [CrossRef]

56. De Vuyst, L. Technology Aspects Related to the Application of Functional Starter Cultures. Food Technol. Biotechnol. 2000, 38, 105-112.

57. Mårtensson, O.; Öste, R.; Holst, O. Texture promoting capacity and EPS formation by lactic acid bacteria in three different oat-based non-dairy media. Eur. Food Res. Technol. 2002, 214, 232-236. [CrossRef]

58. Mårtensson, O.; Öste, R.; Holst, O. Lactic Acid Bacteria in an Oat-based Non-dairy Milk Substitute: Fermentation Characteristics and Exopolysaccharide Formation. LWT Food Sci. Technol. 2000, 33, 525-530. [CrossRef]

59. Polak-Berecka, M.; Wasko, A.; Kubik-Komar, A. Optimization of culture conditions for exopolysaccharide production by a probiotic strain of Lactobacillus rhamnosus E/N. Pol. J. Microbiol. 2014, 63, 253-257. [CrossRef]

60. Tsangalis, D.; Shah, N.P. Metabolism of oligosaccharides and aldehydes and production of organic acids in soymilk by probiotic bifidobacteria. Int. J. Food Sci. Technol. 2004, 39, 541-554. [CrossRef]

61. Aboulfazli, F.; Baba, A.S.; Misran, M. Effects of fermentation by Bifidobacterium bifidum on the rheology and physical properties of ice cream mixes made with cow and vegetable milks. Int. J. Food Sci. Technol. 2015, 50, 942-949. [CrossRef]

62. Granato, D.; Branco, G.F.; Cruz, A.G.; Faria, J.d.A.F.; Shah, N.P. Probiotic dairy products as functional foods. Compr. Rev. Food Sci. Food Saf. 2010, 9, 455-470. [CrossRef]

63. Kechagia, M.; Basoulis, D.; Konstantopoulou, S.; Dimitriadi, D.; Gyftopoulou, K.; Skarmoutsou, N.; Fakiri, E.M. Health Benefits of Probiotics: A Review. ISRN Nutr. 2013. [CrossRef]

64. Ross, A.I.; Tyler, P.; Borgognone, M.G.; Eriksen, B.M. Relationships between shear rheology and sensory attributes of hydrocolloid-thickened fluids designed to compensate for impairments in oral manipulation and swallowing. J. Food Eng. 2019, 263, 123-131. [CrossRef]

65. Bernat Pérez, N. Desarrollo, Caracterización y Optimización de Productos Fermentados a Base de Licuados Vegetales Como Alternativa a los Yogures Convencionales. Ph.D. Thesis, Universidad Politécnica de Valencia, Valencia, Spain, 2013; p. 331.

66. Helland, M.H.; Wicklund, T.; Narvhus, J.A. Growth and metabolism of selected strains of probiotic bacteria, in maize porridge with added malted barley. Int. J. Food Microbiol. 2004, 91, 305-313. [CrossRef]

67. Mishra, B.K.; Hati, S.; Das, S.; Prajapati, J.B. Biofunctional attributes and storage study of soy milk fermented by Lactobacillus rhamnosus and Lactobacillus helveticus. Food Technol. Biotechnol. 2019, 57, 399-407. [CrossRef] 
68. Kpodo, M.K.F.; Afoakwa, E.; Saalia, K.; Amoa, B. Changes in physico-chemical characteristics and volatile flavour components of different yoghurt products made from soy, peanuts and cow milk. Afr. J. Food Agric. Nutr. Dev. 2016, 16, 11278-11294. [CrossRef]

69. Pavunc, A.L.; Penava, L.; Ranilovic, J.; Novak, J.; Banic, M.; Butorac, K.; Petrovic, E.; Mihaljevic-Herman, V.; Bendelja, K.; Mlakar, A.S.; et al. Influence of dehydrated wheat/rice cereal matrices on probiotic activity of Bifidobacterium animalis ssp. lactis BB-12 ${ }^{\circledR}$. Food Technol. Biotechnol. 2019, 57, 147-158. [CrossRef]

70. Watson, D.; O'Connell Motherway, M.; Schoterman, M.H.; van Neerven, R.J.; Nauta, A.; Van Sinderen, D. Selective carbohydrate utilization by lactobacilli and bifidobacteria. J. Appl. Microbiol. 2013, 114, 1132-1146. [CrossRef]

71. Gopal, P.K.; Sullivan, P.A.; Smart, J.B. Utilisation of galacto-oligosaccharides as selective substrates for growth by lactic acid bacteria including Bifidobacterium lactis DR10 and Lactobacillus rhamnosus DR20. Int. Dairy J. 2001, 11, 19-25. [CrossRef]

72. Içier, F.; Gündüz, G.T.; Yilmaz, B.; Memeli, Z. Changes on some quality characteristics of fermented soy milk beverage with added apple juice. LWT Food Sci. Technol. 2015, 63, 57-64. [CrossRef]

73. Grasso, N.; Alonso-Miravalles, L.; O'Mahony, J.A. Composition, physicochemical and sensorial properties of commercial plant-based yogurts. Foods 2020, 9, 252. [CrossRef]

74. Pang, Z.; Luo, Y.; Li, B.; Zhang, M.; Liu, X. Effect of different hydrocolloids on tribological and rheological behaviors of soymilk gels. Food Hydrocoll. 2020, 101, 105558. [CrossRef]

75. Chetachukwu, A.S.; Thongraung, C.; Yupanqui, C.T. Development of reduced-fat coconut yoghurt: Physicochemical, rheological, microstructural and sensory properties. Int. J. Dairy Technol. 2019, 72, 524-535. [CrossRef]

76. Rossa, P.N.; Burin, V.M.; Bordignon-Luiz, M.T. Effect of microbial transglutaminase on functional and rheological properties of ice cream with different fat contents. LWT Food Sci. Technol. 2012, 48, 224-230. [CrossRef]

77. Hui, Y.H. Handbook of Food Science, Technology, and Engineering; CRC Press: Boca Raton, FL, USA, 2006; Volume 3.

78. Girard, M.; Schaffer-Lequart, C. Gelation of skim milk containing anionic exopolysaccharides and recovery of texture after shearing. Food Hydrocoll. 2007, 21, 1031-1040. [CrossRef]

79. Bernat, N.; Cháfer, M.; Chiralt, A.; González-Martínez, C. Vegetable milks and their fermented derivative products. Int. J. Food Stud. 2014, 3, 93-124. [CrossRef]

80. Sutherland, I.W. Bacterial Exopolysaccharides. Compr. Glycosci. Chem. Syst. Biol. 2007, 2-4, 521-558. [CrossRef]

81. Stijepic, M.; Glusac, J.; Durdevic-Milosevic, D.; Pesic-Mikulec, D. Physicochemical characteristics of soy probiotic yoghurt with inulin additon during the refrigerated storage. Rom. Biotechnol. Lett. 2013, 18, 8077-8085.

82. Salazar, N.; Prieto, A.; Leal, J.A.; Mayo, B.; Bada-Gancedo, J.C.; de los Reyes-Gavilán, C.G.; Ruas-Madiedo, P. Production of exopolysaccharides by Lactobacillus and Bifidobacterium strains of human origin, and metabolic activity of the producing bacteria in milk. J. Dairy Sci. 2009, 92, 4158-4168. [CrossRef]

83. Grygorczyk, A. A Novel Approach to Structure Generation for Texture Improvement in a Soymilk-Dairy Gel. Ph.D. Thesis, University of Guelph, Guelph, ON, Canada, 2012.

84. Aboulfazli, F.; Baba, A.S.; Misran, M. The Rheology and Physical Properties of Fermented Probiotic Ice Creams Made with Dairy Alternatives. Int. J. Food Eng. 2015, 11, 493-504. [CrossRef]

85. Brückner-gühmann, M.; Banovic, M.; Drusch, S. Food Hydrocolloids Towards an increased plant protein intake: Rheological properties, sensory perception and consumer acceptability of lactic acid fermented, oat-based gels. Food Hydrocoll. 2019, 96, 201-208. [CrossRef]

86. Pujala, R.K. Dispersion Stability, Microstructure and Phase Transition of Anisotropic Nanodiscs; Springer: Berlin, Germany, 2014.

87. Buldo, P.; Benfeldt, C.; Folkenberg, D.M.; Jensen, H.B.; Amigo, J.M.; Sieuwerts, S.; Thygesen, K.; van den Berg, F.; Ipsen, R. The role of exopolysaccharide-producing cultures and whey protein ingredients in yoghurt. LWT Food Sci. Technol. 2016, 72, 189-198. [CrossRef]

88. Wang, Y.C.; Yu, R.C.; Yang, H.Y.; Chou, C.C. Sugar and acid contents in soymilk fermented with lactic acid bacteria alone or simultaneously with bifidobacteria. Food Microbiol. 2003, 20, 333-338. [CrossRef] 
89. Meurman, J.; Antila, H.; Korhonen, A.; Salminen, S. Effect of Lactobacillus rhamnosus strain GG (ATCC 53103) on the growth of Streptococcus sobrinus in vitro. Eur. J. Oral Sci. 1995, 103. [CrossRef]

90. Hedberg, M.; Hasslöf, P.; Sjöström, I.; Twetman, S.; Stecksén-Blicks, C. Sugar fermentation in probiotic bacteria-An in vitro study. Oral Microbiol. Immunol. 2008, 23, 482-485. [CrossRef]

91. Cheng, H. Volatile flavor compounds in yogurt: A review. Crit. Rev. Food Sci. Nutr. 2010, 50, 938-950. [CrossRef]

92. Ricci, A.; Cirlini, M.; Maoloni, A.; Del Rio, D.; Calani, L.; Bernini, V.; Galaverna, G.; Neviani, E.; Lazzi, C. Use of Dairy and Plant-Derived Lactobacilli as Starters for Cherry Juice Fermentation. Nutrients 2019, 11, 213. [CrossRef] [PubMed]

93. Beshkova, D.M.; Simova, E.D.; Frengova, G.I.; Simov, Z.I.; Dimitrov, Z.P. Production of volatile aroma compounds by kefir starter cultures. Int. Dairy J. 2003, 13, 529-535. [CrossRef]

94. Morales, P.; Feliu, I.; Fernández-García, E.; Nuñez, M. Volatile compounds produced in cheese by Enterobacteriaceae strains of dairy origin. J. Food Prot. 2004, 67, 567-573. [CrossRef] [PubMed]

95. Irigoyen, A.; Ortigosa, M.; García, S.; Ibáñez, F.C.; Torre, P. Comparison of free amino acids and volatile components in three fermented milks. Int. J. Dairy Technol. 2012, 65, 578-584. [CrossRef]

96. Kaneko, D.; Igarashi, T.; Aoyama, K. Reduction of the off-flavor volatile generated by the yogurt starter culture including streptococcus thermophilus and Lactobacillus delbrueckii subsp. bulgaricus in soymilk. J. Agric. Food Chem. 2014, 62, 1658-1663. [CrossRef] [PubMed]

97. Granata, L.A.; Morr, C.V. Improved acid, flavor and volatile compound production in a high protein and fiber soymilk yogurt-like product. J. Food Sci. 1996, 61, 331-336. [CrossRef]

98. Yan Chun, L.; Song, H.L.; Li, X.; Wu, L.; Guo, S.T. Influence of Blanching and Grinding Process with Hot Water on Beany and Non-Beany Flavor in Soymilk. J. Food Sci. 2011, 76, 20-25. [CrossRef]

99. Valero, E.; Villamiel, M.; Miralles, B.; Sanz, J.; Martínez-Castro, I. Changes in flavour and volatile components during storage of whole and skimmed UHT milk. Food Chem. 2001, 72, 51-58. [CrossRef]

100. Salmenkallio-Marttila, M.; Heiniö, R.L.; Kaukovirta-Norja, A.; Poutanen, K. Flavor and Texture in Processing of New Oat Foods, 2nd ed.; AACC International, Inc.: Eagan, Minnesota, 2011; pp. 333-346. [CrossRef]

101. Lee, S.M.; Oh, J.; Hurh, B.S.; Jeong, G.H.; Shin, Y.K.; Kim, Y.S. Volatile Compounds Produced by Lactobacillus paracasei During Oat Fermentation. J. Food Sci. 2016, 81, C2915-C2922. [CrossRef]

102. Natrella, G.; Faccia, M.; Lorenzo, J.M.; De Palo, P.; Gambacorta, G. Short communication: Sensory characteristics and volatile organic compound profile of high-moisture mozzarella made by traditional and direct acidification technology. J. Dairy Sci. 2020, 103, 2089-2097. [CrossRef]

103. Dan, T.; Wang, D.; Wu, S.; Jin, R.; Ren, W.; Sun, T. Profiles of Volatile Flavor Compounds in Milk Fermented with Different Proportional Combinations of Lactobacillus delbrueckii subsp. bulgaricus and Streptococcus thermophilus. Molecules 2017, 22, 1633. [CrossRef]

104. Achouri, A.; Boye, J.I.; Zamani, Y. Changes in soymilk quality as a function of composition and storage. J. Food Qual. 2007, 30, 731-744. [CrossRef]

105. Kaczmarska, K.T.; Chandra-Hioe, M.V.; Frank, D.; Arcot, J. Aroma characteristics of lupin and soybean after germination and effect of fermentation on lupin aroma. LWT Food Sci. Technol. 2018, 87, 225-233. [CrossRef]

106. Borse, B.B.; Rao, L.J.M.; Ramalakshmi, K.; Raghavan, B. Chemical composition of volatiles from coconut sap (neera) and effect of processing. Food Chem. 2007, 101, 877-880. [CrossRef]

107. Santos, J.E.R.; Villarino, B.J.; Zosa, A.R.; Dayrit, F.M. Analysis of volatile organic compounds in virgin coconut oil and their sensory attibutes. Philipp. J. Sci. 2011, 140, 161-171.

108. Sides, A.; Robards, K.; Helliwell, S.; An, M. Changes in the volatile profile of oats induced by processing. J. Agric. Food Chem. 2001, 49, 2125-2130. [CrossRef]

109. Hassan, F.A.; Abd El-Gawad, M.A.; Enab, A. Flavour compounds in cheese (Review). Int. J. Acad. Res. 2012, 4. [CrossRef]

110. Wang, Y.; Yang, X.; Li, L. A new style of fermented tofu by Lactobacillus casei combined with salt coagulant. 3 Biotech 2020, 10, 1-8. [CrossRef]

111. Ahmad, N.; Li, L.; Yang, X.Q.; Ning, Z.X.; Randhawa, M.A. Improvements in the flavour of soy cheese. Food Technol. Biotechnol. 2008, 46, 252-261.

112. Vazquez-Landaverde, P.A.; Velazquez, G.; Torres, J.A.; Qian, M.C. Quantitative determination of thermally derived off-flavor compounds in milk using solid-phase microextraction and gas chromatography. J. Dairy Sci. 2005, 88, 3764-3772. [CrossRef] 
113. van der Schaft, P.H.; ter Burg, N.; van den Bosch, S.; Cohen, A.M. Fed-batch production of 2-heptanone by Fusarium poae. Appl. Microbiol. Biotechnol. 1992, 36, 709-711. [CrossRef]

114. Cognat, C.; Shepherd, T.; Verrall, S.R.; Stewart, D. Comparison of two headspace sampling techniques for the analysis of off-flavour volatiles from oat based products. Food Chem. 2012, 134, 1592-1600. [CrossRef] [PubMed]

115. Zhang, Q.; Zhong, J.; Wang, F.; Song, H.; Huang, W..; Rayas-Duarte, P. Flavor Character of Bread with Oat Sourdough Fermented by Lactobacillus plantarum-Journal of Beijing Technology and Business University (Natural Science Edition). J. Beijing Technol. Bus. Univ. 2011, 29, 12-18.

116. Dufosse, L.; Latrasse, A.; Spinnler, H.E. Importance of Lactones in Food Flavors-Structure, Distribution, Sensory Properties and Biosynthesis. Sci. Aliment. 1994, 14, 17-50.

117. de Souza Oliveira, R.P.; Perego, P.; de Oliveira, M.N.; Converti, A. Effect of inulin on the growth and metabolism of a probiotic strain of Lactobacillus rhamnosus in co-culture with Streptococcus thermophilus. LWT Food Sci. Technol. 2012, 47, 358-363. [CrossRef]

118. Dresselhuis, D.M.; de Hoog, E.H.; Cohen Stuart, M.A.; Vingerhoeds, M.H.; van Aken, G.A. The occurrence of in-mouth coalescence of emulsion droplets in relation to perception of fat. Food Hydrocoll. 2008, 22, 1170-1183. [CrossRef]

(C) 2020 by the authors. Licensee MDPI, Basel, Switzerland. This article is an open access article distributed under the terms and conditions of the Creative Commons Attribution (CC BY) license (http:/ / creativecommons.org/licenses/by/4.0/). 